\title{
Simulation of Gas Transport in A Landfill With Layered New and Old Municipal Solid Waste
}

\author{
Tao Zhang ( $\nabla$ taozhanggeo@outlook.com ) \\ Nanchang Hangkong University \\ Jianyong Shi \\ Hohai University \\ Xun Wu \\ Hohai University \\ Hai Lin \\ Nanchang University \\ Xiulei Li \\ Chongqing Jiaotong University
}

\section{Research Article}

Keywords: Numerical calculation, Gas pressure, Stratification, New and old waste layers, Landfill

Posted Date: February 3rd, 2021

DOI: https://doi.org/10.21203/rs.3.rs-151628/v1

License: (c) (i) This work is licensed under a Creative Commons Attribution 4.0 International License.

Read Full License 


\section{Simulation of gas transport in a landfill with layered new and old municipal solid waste}

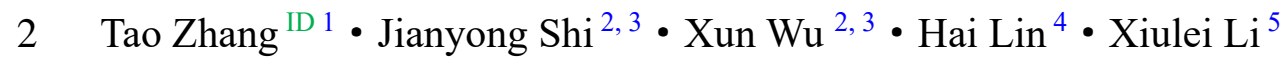

31 School of Civil Engineering and Architecture, Nanchang Hangkong University, Nanchang

4330063 , China

$5 \quad{ }^{2}$ Geotechnical Engineering Research Institute, Hohai University, Nanjing 210098, China

$6{ }^{3}$ Key Laboratory of Ministry of Education for Geomechanics and Embankment Engineering,

7 Hohai University, Nanjing 210098, China

$8{ }^{4}$ School of Civil Engineering and Architecture, Nanchang University, Nanchang 330031, China

$9{ }^{5}$ College of Hohai, Chongqing Jiaotong University, Chongqing 400074, China

10 Correspondence and requests for materials should be addressed to T.Z. (email:

11 taozhanggeo@outlook.com).

12 ORCID ID: http://orcid.org/0000-0003-2981-0990

\section{Abstract}

Average biodegradation rate of newly filled municipal solid waste (MSW) in landfills is

15 relatively fast, and the landfill gas produced by the new MSW biodegradation can cause great

16 variations in gas pressure. To predict the gas pressure distribution in the MSW layer, a one-

17 dimensional gas transport model is established in this study. The following factors are considered

18 in this model: (1) the variation of gas permeability with depth; (2) the anisotropy ratio of gas

19 permeability; (3) the settlement caused by waste biodegradation. Furthermore, a single peak model

20 for gas production is applied as the source term of gas production. The equation for settlement

21 caused by waste biodegradation is presented, and the time of peak gas production rate is obtained

22 by fitting the settlement of the newly filled layer. The stratification of the unsaturated and saturated

23 regions is taken into account by distinguishing the difference in gas saturation. The layering of the

24 new and old waste layers is considered by distinguishing the difference in the length of time that

25 waste has been degraded to produce gas. Based on the method of numerical calculation, the gas 
26 pressure distribution in the landfill with layered new and old MSW is well simulated. The position

27 where the maximum gas pressure occurs is found. The sensitivity analysis shows that the influence

28 of the anisotropy ratio on gas pressure distribution is more significant.

29 Keywords Numerical calculation - Gas pressure - Stratification - New and old waste

30 layers $\cdot$ Landfill

\section{Instruction}

The continuous generation of gas in landfills causes landfill gas to escape into the atmosphere

33 due to pressure differences ${ }^{1-4}$. Additionally, slope instability caused by changes in landfill gas

34 pressure often occurs ${ }^{5-7}$. Therefore, the exploration of gas pressure and its distribution in landfills

35 has become an important research area. Kjeldsen and Fischer ${ }^{8}$ monitored the gas pressure in the

36 old waste layer of Skellingsted landfill for 35 days, and results show that the variation of gas

37 pressure in the landfill has a great influence on the composition of landfill gas. Spokas and Bogner ${ }^{9}$

38 and Bentley et al. ${ }^{10}$ measured gas pressure in the Olinda and Louisiana landfills for 3 and 5 days,

39 respectively, and found that the measured pressure is influenced by fluctuations in atmospheric

40 pressure. Gebert and Groengroft ${ }^{11}$ found that the amplitude of the gas pressure measured in two

41 gas collection wells in an old German landfill exhibits a linear correlation with the amplitude of

42 atmospheric pressure. Zhang et al. ${ }^{12}$ observed the gas pressure in the newly filled municipal solid

43 waste (MSW) layer of the Wuxi landfill for more than 500 days, with results showing that the gas

44 pressure varies with time, showing a single peak curve. The stratification of new and old waste

45 layers is constantly occurring in operating landfills ${ }^{12-14}$. The variation of gas pressure over time in 
this landfill needs to be estimated by theoretical calculation.

At present, many scholars have obtained the gas pressure distribution in landfills through numerical $^{1,15-24}$ and analytical ${ }^{25-29}$ calculations. Current research is mainly based on the theory to

49 estimate the gas pressure in landfills as the data of gas pressure distribution in the field is rarely

50 reported, and estimation of gas pressure through the combination of the field data and theoretical

51 analysis is relatively scarce. Moreover, landfills in these studies are generally regarded as landfills

52 with a homogeneously unsaturated waste layer ${ }^{1,15-17,19,24-29}$ or a continuously placed waste layer ${ }^{20,}$

53 22-23, 28-29. Findikakis and Leckie ${ }^{15}$, Findikakis et al. ${ }^{16}$, and Liu et al. ${ }^{27}$ considered the increasing

54 stage of gas production rate, and Lu et al. ${ }^{23}$ considered the anisotropic ratio of gas permeability.

55 The working conditions for the stratification of new and old waste and the stratification of saturated

56 and unsaturated waste in an operating landfill were investigated by Zhang et al. ${ }^{12}$, but current

57 research methods have not considered these two working conditions. If the gas pressure

58 distribution in the landfill needs to be estimated, it is necessary to consider the increasing stage of

59 gas production rate and the anisotropy ratio of gas permeability. In addition, the stratification of

60 new and old waste and the stratification of saturated and unsaturated waste should also be

61 considered.

62 Based on numerical methods, a one-dimensional gas transport model for estimating the gas

63 pressure in a landfill with layered new and old waste and layered saturated and unsaturated waste

64 is presented in this study. The factors considered in this model are as follow: firstly, the

65 stratification of the length of time that waste has been degraded, gas permeability, and porosity;

66 secondly, the anisotropy ratio of gas permeability; thirdly, the settlement caused by waste 
67 biodegradation; fourthly, the source term of gas production. The equation for quantifying

68 settlement induced by waste biodegradation is presented, and the time of peak gas production rate

69 is obtained by fitting the settlement of the new waste layer with this equation. The stratification of

70 the unsaturated and saturated zones is considered by distinguishing the gas saturation in the

71 different zones. The stratification of the new and old waste layers is considered by distinguishing

72 the length of time that the waste has been degraded to produce gas in the different waste layers.

73 The results of the numerical calculation are then compared with the gas pressure in the newly filled

74 waste layer measured by Zhang et al. ${ }^{12}$. The validity of the calculation method and the theoretical

75 model in simulating the gas pressure distribution in the newly filled waste layer is determined, and

76 the evolution of the gas pressure distribution in the landfill with layered new and old waste layers

77 is analyzed. The position of the maximum gas pressure and the significant sensitive parameter of

78 the gas pressure distribution are found.

79 Materials and Methods

80 Numerical Model for Gas Transport

81 To establish a model for predicting gas pressure in landfills, it is assumed that gas transport in

82 the MSW layer follows Darcy's law, and settlement only occurs in the vertical direction. According

83 to the mass conservation law, the net mass of gas flowing into and out of the unit body plus the

84 mass of gas production equal to the variation of gas mass in the unit body, which can be represented

85 by the following equation: 


$$
-\left(\frac{\partial \rho_{g} V_{x}}{\partial x} d x+\frac{\partial \rho_{g} V_{y}}{\partial y} d y+\frac{\partial \rho_{g} V_{z}}{\partial z} d z\right) d t+\rho_{g} Q_{G} d x d y d z d t=\frac{\partial \rho_{g} n S_{g} d x d y d z}{\partial t} d t
$$

87 where $\rho_{g}$ is the density of landfill gas $\left(\mathrm{kg} \mathrm{m}^{-3}\right) ; V_{x}, V_{y}$ and $V_{z}$ are the volumes of landfill gas entering

88 the unit body along directions $o x, o y$ and $o z$ per unit time $\left(\mathrm{m}^{3} \mathrm{~d}^{-1}\right)$, respectively; $Q_{G}$ is the volume

89 of gas produced by biodegradation per unit volume of waste per unit time $\left(\mathrm{d}^{-1}\right)$; $n$ is the porosity

90 of waste; $S_{g}$ is the gas saturation.

91 Following Darcy"s law, the following equation is obtained:

$$
V_{i}=-\frac{K_{g i}}{\mu_{g}} P_{g, i} d j d k
$$

93 where $i, j$ or $\mathrm{k}=x, y$, or $z(i \neq j \neq k) ; K_{g i}$ is the gas permeability in the direction $i\left(m^{2}\right)$; $\mu_{g}$ is the gas

94 dynamic viscosity $(\mathrm{Pa} \mathrm{s}) ; P_{g}$ is gas pressure $(\mathrm{kPa})$.

95 When the settlement caused by waste biodegradation in landfills is considered, the following

96 equation can be obtained:

97

$$
\frac{\partial d z}{\partial t}=d z \frac{d \varepsilon_{t}}{d t}
$$

98 where $\varepsilon_{t}$ is the biodegradation settlement strain of the landfill.

99 According to the ideal gas law, the following equation can be obtained:

100

$$
\rho_{g}=\frac{\left(P_{g}+P_{a t m}\right) M_{g}}{R T}
$$

101 where $P_{\text {atm }}$ is atmospheric pressure $(\mathrm{kPa}) ; M_{g}$ is the molar mass of landfill gas $\left(\mathrm{g} \mathrm{mol}^{-1}\right) ; R$ is the 102 gas constant $\left(\mathrm{J}(\mathrm{mol} \mathrm{K})^{-1}\right) ; T$ is waste temperature $\left({ }^{\circ} \mathrm{C}\right)$.

103 According to the equation of waste biodegradation rate presented by Liu et al. ${ }^{27}$, and waste 104 can be divided into easily degraded, moderately degraded, and difficultly degraded according to 
105 the biodegradability of the waste ${ }^{19,30-31}$. The volume of landfill gas generated by biodegradation

106 per unit volume of waste per unit time can be presented, as is shown in the following equation:

$$
Q_{G}=\rho L_{0} \sum_{i=1}^{3} \omega_{i} \frac{A_{G i}}{B_{G i}}\left(t+D_{G i}\right) e^{-\frac{t+D_{G i}}{B_{G i}}}
$$

108 where $\rho$ is the density of waste $\left(\mathrm{kg} \mathrm{m}^{-3}\right) ; L_{0}$ is the volume of landfill gas generated by biodegradable

109 per unit mass of waste $\left(\mathrm{m}^{3} \mathrm{~kg}^{-1}\right) ; i=1, i=2$, and $i=3$ represent easily degraded, moderately degraded

110 and difficultly degraded component in waste, respectively; $\omega_{i}$ is the proportion of component; $A_{G i}$

111 is the parameter related to gas production rate $\left(\mathrm{d}^{-1}\right) ; B_{G i}$ is the time of peak gas production rate $(\mathrm{d})$;

$112 D_{G i}$ is the length of time that the waste has been degraded to produce gas (d).

113 To facilitate the calculation of the settlement caused by waste biodegradation, the landfill is

114 simplified into the schematic diagram shown in Fig. 1. Based on Fig. 1, the settlement strain of a

115 landfill can be presented (Specific processes are shown in the Appendix), as is shown in the

116 following equation:

$$
\varepsilon_{t}=\sum_{i=1}^{3}\left\{1-\frac{1}{e_{0}+1}\left[e_{0}-C_{c} \lg \left(1+\frac{t}{t_{D}}\right)+1\right]\left[1-A_{G i} \times B_{G i}\left(-\frac{t}{B_{G i}} e^{-\frac{t}{B_{G i}}}+1-e^{-\frac{t}{B_{G i}}}\right)\right]\right\},
$$

118 where $\lambda_{t}$ is waste biodegradation rate; $m_{s 0}$ is the waste mass at the initial moment; $m_{s t}$ is the waste

119 mass at the moment $t ; V_{s 0}$ is the waste volume at the initial moment; $V_{s t}$ is the waste volume at the

120 moment $t ; h_{0}$ is the initial height of landfill; $h_{t}$ is the height of landfill at time $t ; e_{0}$ is the initial void

121 ratio; $e_{t}$ is the void ratio at time $t$. 
Initial time

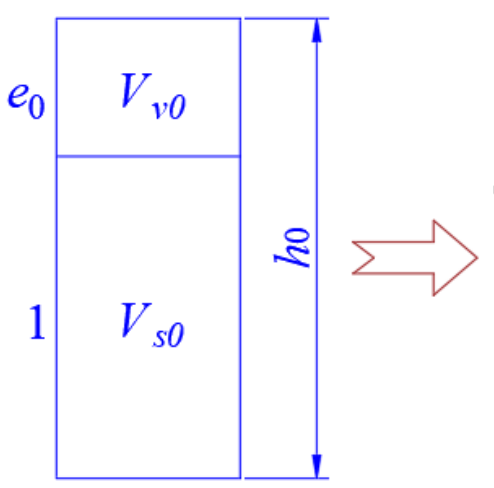

Time $t$

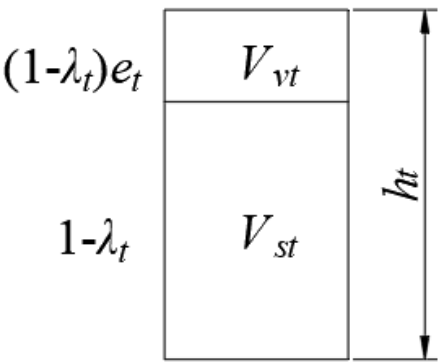

Fig. 1 Schematic diagram of simplified landfill

124 Substituting Eqs. (2) - (6) into Eq. (1), since the pressure of landfill gas is a very small value

125 compared with the atmospheric pressure, then the pressure of landfill gas can be neglected when

126 the sum of the gas pressure in landfills and the atmospheric pressure is calculating ${ }^{29-30,32-33}$. The

127 gas pressure distribution in the landfill is a one-dimensional problem, because the landfill gas is

128 only considered to migrate to the outside and into the old waste layer. Therefore, the following

129 equation can be obtained:

130

$$
\begin{aligned}
& \frac{K_{g z}}{u_{g}} \frac{\partial^{2} P_{g}}{\partial z^{2}}+\frac{1}{u_{g}} \frac{\partial K_{g z}}{\partial z} \frac{\partial P_{g}}{\partial z}+\rho L_{0} \sum_{i=1}^{3} \omega_{i} \frac{A_{G i}}{B_{G i}}\left(t+D_{G i}\right) e^{-\frac{t+D_{G i}}{B_{G i}}}- \\
& n S_{g}\left\{\begin{array}{l}
1+\frac{1}{e_{0}+1}\left[e_{0}-C_{c} \lg \left(1+\frac{t}{t_{D}}\right)+1\right] \frac{A_{G i} t}{B_{G i}} e^{-\frac{t}{B_{G i}}}+ \\
\left.\frac{C_{c}}{\left(e_{0}+1\right)\left(t+t_{D}\right) \ln 10}\left[1-A_{G i} \times B_{G i}\left(-\frac{t}{B_{G i}} e^{-\frac{t}{B_{G i}}}+1-e^{-\frac{t}{B_{G i}}}\right)\right]\right\}=\frac{n S_{g}}{P_{a t m}} \frac{\partial P_{g}}{\partial t}
\end{array}\right\}
\end{aligned}
$$

132 layer.

133 The following equation can be obtained by differencing Eq. (7): 


$$
f_{G 1} \frac{P_{g k-1}^{t}-2 P_{g k}^{t}+P_{g k+1}^{t}}{h_{z}^{2}}+f_{G 2} \frac{P_{g k+1}^{t}-P_{g k-1}^{t}}{2 h_{z}}+f_{G 3}=f_{G 4} \frac{P_{g k}^{t}-P_{g k}^{t-1}}{\tau},
$$

135 where $f_{G 1}=\frac{K_{g z}}{\mu_{g}} ; f_{G 2}=\frac{1}{\mu_{g}} \frac{\partial K_{g z}}{\partial z} ;$

136

$$
\begin{aligned}
& f_{G 3}=\rho L_{0} \sum_{i=1}^{3} \omega_{i} \frac{A_{G i}}{B_{G i}}\left(t+D_{G i}\right) e^{-\frac{t+D_{G i}}{B_{G i}}}- \\
& n S_{g}\left\{\begin{array}{l}
1+\frac{1}{e_{0}+1}\left[e_{0}-C_{c} \lg \left(1+\frac{t}{t_{D}}\right)+1\right] \frac{A_{G i} t}{B_{G i}} e^{-\frac{t}{B_{G i}}}+ \\
\frac{C_{c}}{\left(e_{0}+1\right)\left(t+t_{D}\right) \ln 10}\left[1-A_{G i} \times B_{G i}\left(-\frac{t}{B_{G i}} e^{-\frac{t}{B_{G i}}}+1-e^{-\frac{t}{B_{G i}}}\right)\right]
\end{array}\right\} ; f_{G 4}=\frac{n S_{g}}{P_{a t m}} ;
\end{aligned}
$$

$137 h_{z}$ is the step length in the vertical direction; $\tau$ is the step length of time.

Eq. (8) is the difference equation of a one-dimensional transient difference scheme for gas transport in a landfill. The difference equation is in the classical implicit format, indicating that the difference equation can be solved via iterative methods.

\section{Verification of Numerical Method}

In this study, the gas pressure in the new and old waste layers is calculated based on the

143 defined numerical calculation method. In order to verify the reliability of this method, the

144 mathematical model of gas transport presented by Li et al. ${ }^{29}$ is calculated with new method, and

145 the numerical results are compared with the original analytical results. The mathematical model of

146 gas transport presented by Li et al. ${ }^{29}$ is shown in Eq. (9), respectively: 


$$
\left\{\begin{array}{l}
\text { Governing equation: } \frac{\partial P_{g}}{\partial t}=\alpha_{L} \frac{\partial^{2} P_{g}}{\partial z^{2}}+\beta_{L} e^{-k_{L}\left(t+z / r_{L}\right)} \\
\text { Initial condition: } P_{g}(z, t=0)=0 \\
\text { Upper boundary: } P_{g}(z=0, t)=0 \\
\text { Lower boundary: } \frac{\partial P_{g}\left(z=H_{L}, t\right)}{\partial z}=0
\end{array},\right.
$$

148 where $\alpha_{L}=\frac{P_{a t m} K_{G}}{n_{g L} \mu_{L}} ; \beta_{L}=\frac{R T_{L}}{n_{g_{L}} \omega_{L}} L_{g} k_{L} ; P_{g}$ is gas pressure $(\mathrm{kPa}) ; P_{a t m}$ is atmospheric pressure

$149(101.3 \mathrm{kPa}) ; K_{G}$ is gas permeability $\left(6.9 \times 10^{-13} \mathrm{~m}^{2}\right) ; n_{g}$ is gas content $(0.5) ; \mu_{L}$ is gas dynamic

150 viscosity $\left(1.37 \times 10^{-5} \mathrm{~kg}\left(\mathrm{~m} \mathrm{~s}^{-1}\right) ; R\right.$ is gas constant $\left(8.31 \mathrm{~J}(\mathrm{~K} \mathrm{~mol})^{-1}\right) ; T_{L}$ is gas temperature

$151\left(298{ }^{\circ} \mathrm{C}\right) ; \omega_{L}$ is the molar mass of gas $\left(0.03 \mathrm{~g} \mathrm{~mol}^{-1}\right) ; L_{g}$ is the mass of gas produced by the waste

152 of unit volume $\left(230 \mathrm{~kg} \mathrm{~m}^{-3}\right) ; k_{L}$ is the constant of gas production rate $\left(0.1 \mathrm{year}^{-1}\right) ; r_{L}$ is the waste

153 placing rate $\left(3 \mathrm{~m} \mathrm{year}^{-1}\right) ; H_{L}$ is the thickness of landfill $(30 \mathrm{~m})$.

154 When Eq. (9) is differenced, the numerical model for calculating the gas pressure in the study

155 of Li et al. ${ }^{29}$ can be obtained as follow:

$$
\left\{\begin{array}{l}
\text { Governing equation: } \frac{P_{g k}^{t}-P_{g}^{t-1} k}{\tau}=\alpha_{L} \frac{P_{g k-1}^{t}-2 P_{g k}^{t}+P_{g k+1}^{t}}{h_{z}^{2}}+\beta_{L} e^{-k_{L}\left[t+h_{z}(k-1) / r_{L}\right]} \\
\text { Initial condition: } P_{g k}^{t=o t(0)}=0 \\
\text { Upper boundary }: P_{g k=o z(0)}^{t}=0 \\
\text { Lower boundary }: P_{g k=o z\left(H_{L}\right)}^{t}=P_{g k-1=o z\left(H_{L}\right)-1}^{t}
\end{array},\right.
$$

157 where, $h_{z}$ is the step length in the vertical direction; $\tau$ is the step length of time; oz $(z)$ and $o t(t)$ are

158 the node functions in the vertical direction and time, respectively. calculation method, as is shown in Fig. 2. It can be found that the curve of gas pressure with depth

161 obtained by using the numerical calculation method in this study closely matches the curve of gas 
162 pressure with depth obtained by Li et al. ${ }^{29}$ using their analytical method, illustrating the reliability

163 of the numerical method used in this study.

164

165

166

167 impermeable boundary condition (Neumann boundary condition) in the numerical calculation.

173 Generally, when the gas pressure in an uncovered landfill is calculated, the upper boundary is 174 regarded as the atmospheric pressure, that is, the relative gas pressure is zero ${ }^{16-17,19-20,22,24,26,28-29}$. 175 However, in order to reasonably simulate the upper boundary of the Wuxi landfill, the gas pressure

Fig. 2 Comparison of the calculation values of gas pressure in this study and the value calculated by Li et al. ${ }^{29}$

\section{Results and Discussion}

\section{Gas Pressure Distribution in the Wuxi Landfill}

The leachate drainage and liner systems at the bottom of the Wuxi landfill, where Zhang et al. ${ }^{12}$ conducted their field test, were built in 1995 . There is not a landfill gas extraction system at the bottom. Therefore, the boundary condition at the bottom of the landfill can be considered as an Generally, when the gas pressure in an uncovered landfill is calculated, the upper boundary is

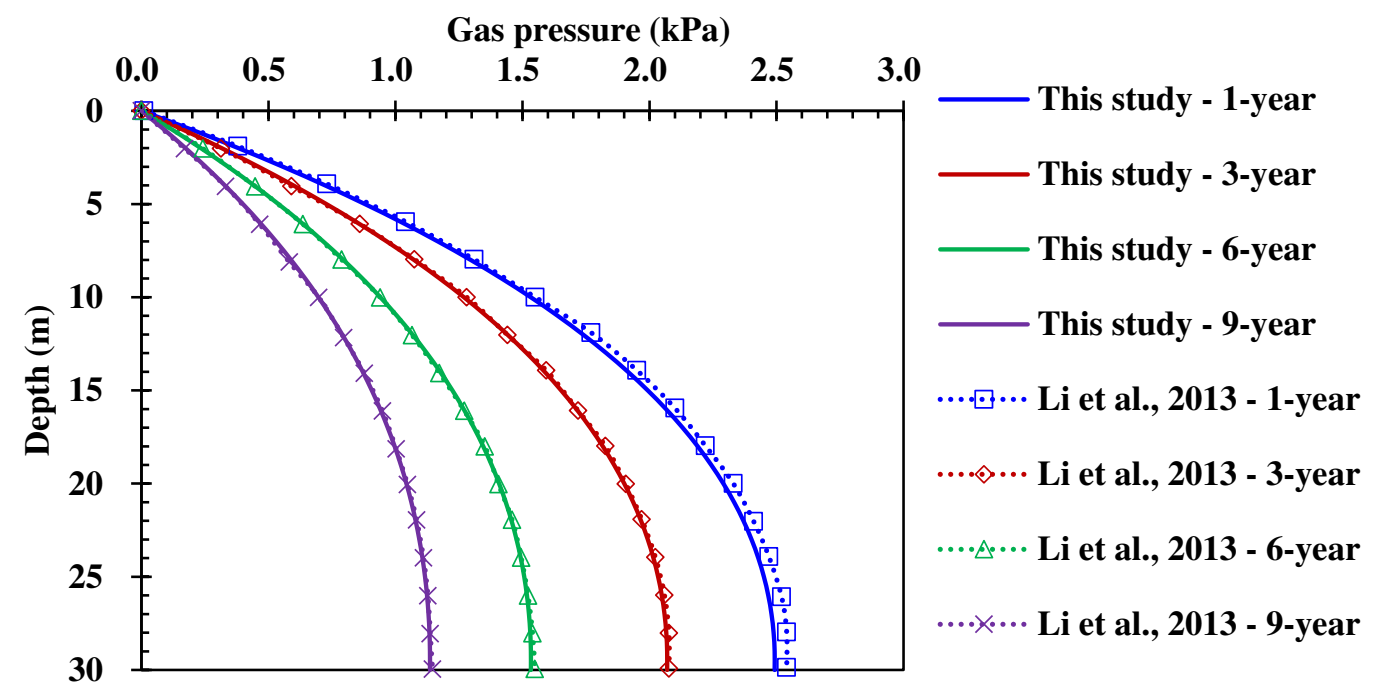


176 at the shallowest depth (depth: $1.3 \mathrm{~m}$ ) observed by Zhang et al. ${ }^{12}$ is used as the upper boundary

177 (Dirichlet boundary condition). The gas pressure at this depth is fitted with a single peak function,

178 and the fitting result is shown in the top of Fig. 3. The initial gas pressure is $0 \mathrm{kPa}$, because the

179 method for burying gas collection and monitoring wells during a field test is to excavate the waste

180 body $^{12}$. The physical model for simulating gas transport in the Wuxi landfill is shown in Fig. 3.

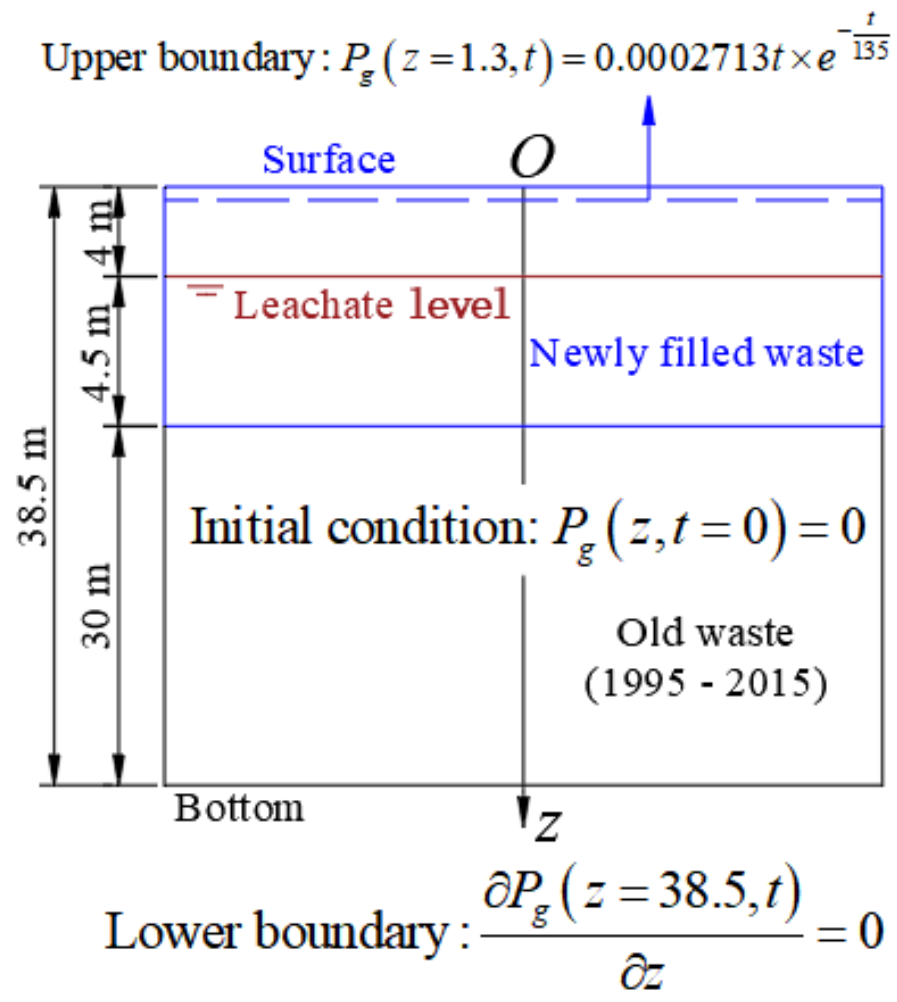

183 According to Eq. (7) and Fig. 3, the following mathematical model can be obtained: 


$$
\left\{\begin{array}{l}
n S_{g}\left\{\begin{array}{l}
1+\frac{1}{e_{0}+1}\left[e_{0}-C_{c} \lg \left(1+\frac{t}{t_{D}}\right)+1\right] \frac{A_{G i} t}{B_{G i}} e^{-\frac{t}{B_{G i}}}+ \\
\frac{C_{c}}{\left(e_{0}+1\right)\left(t+t_{D}\right) \ln 10}\left[1-A_{G i} \times B_{G i}\left(-\frac{t}{B_{G i}} e^{-\frac{t}{B_{G i}}}+1-e^{-\frac{t}{B_{G i}}}\right)\right]
\end{array}\right\}=\frac{n S_{g}}{P_{a t m}} \frac{\partial P_{g}}{\partial t} \\
\text { Initial condition: } P_{g}(z, t=0)=0 \\
\text { Upper boundary : } P_{g}(z=1.3, t)=0.0002713 t \times e^{-\frac{t}{135}} \\
\text { Lower boundary }: \frac{\partial P_{g}(z=38.5, t)}{\partial z}=0
\end{array}\right.
$$

$$
\left\{\begin{array}{l}
\text { Governing equation: } f_{G 1} \frac{P_{g k-1}^{t}-2 P_{g k}^{t}+P_{g k+1}^{t}}{h_{z}^{2}}+f_{G 2} \frac{P_{g k+1}^{t}-P_{g k-1}^{t}}{2 h_{z}}+f_{G 3}=f_{G 4} \frac{P_{g k}^{t}-P_{g k}^{t-1}}{\tau} \\
\text { Initial condition: } P_{g k}^{t=o t(0)}=0 \\
\text { Upper boundary: } P_{g k=o z(1.3)}^{t}=0.0002713[o t(t)-1] \tau \times e^{-\frac{[o t(t)-1] \tau}{135}} \\
\text { Lower boundary: } P_{g k=o z(38.5)}^{t}=P_{g k=o z(38.5)-1}^{t}
\end{array},\right.
$$

188 where $\tau$ is the step length of time; $o t(t)$ and $o z(z)$ are the node functions in time and the vertical 189 direction, respectively.

190 The gas pressure distribution in the monitoring test conducted by Zhang et al. ${ }^{12}$ is studied, 191 and the layout of the field test site can be viewed in the paper of Zhang et al. ${ }^{12}$. In order to select 192 reasonable calculation parameters, the parameters which are suitable for the Wuxi landfill are 193 selected. The parameters used in the numerical calculation are shown in Table 1. In the process of 194 numerical calculation, the step length in the vertical direction is $0.5 \mathrm{~m}$ and the step length of time 
195 is one day. The equation of gas transport in this study is a parabolic equation, and its difference

196 scheme (Eq. (8)) is a classical implicit scheme. Therefore, the iterative method is used to solve the

197 difference equation with absolute convergence using any mesh ratio. The stratification of the

198 unsaturated and saturated waste is realized by distinguishing the gas saturation above and below

199 the leachate level. The stratification of the new and old waste is realized by distinguishing the

200 length of time that waste has been degraded to produce gas in the new and old waste layers. In

201 addition, in order to simulate the actual landfill, the variations of gas permeability and porosity

202 with depth, the anisotropic ratio of gas permeability, and the settlement caused by waste

203 biodegradation were also considered.

204

205

206

207

208

209

210

211

212

213

214

215 
216 Table 1 Parameters of gas transport model in the Wuxi landfill

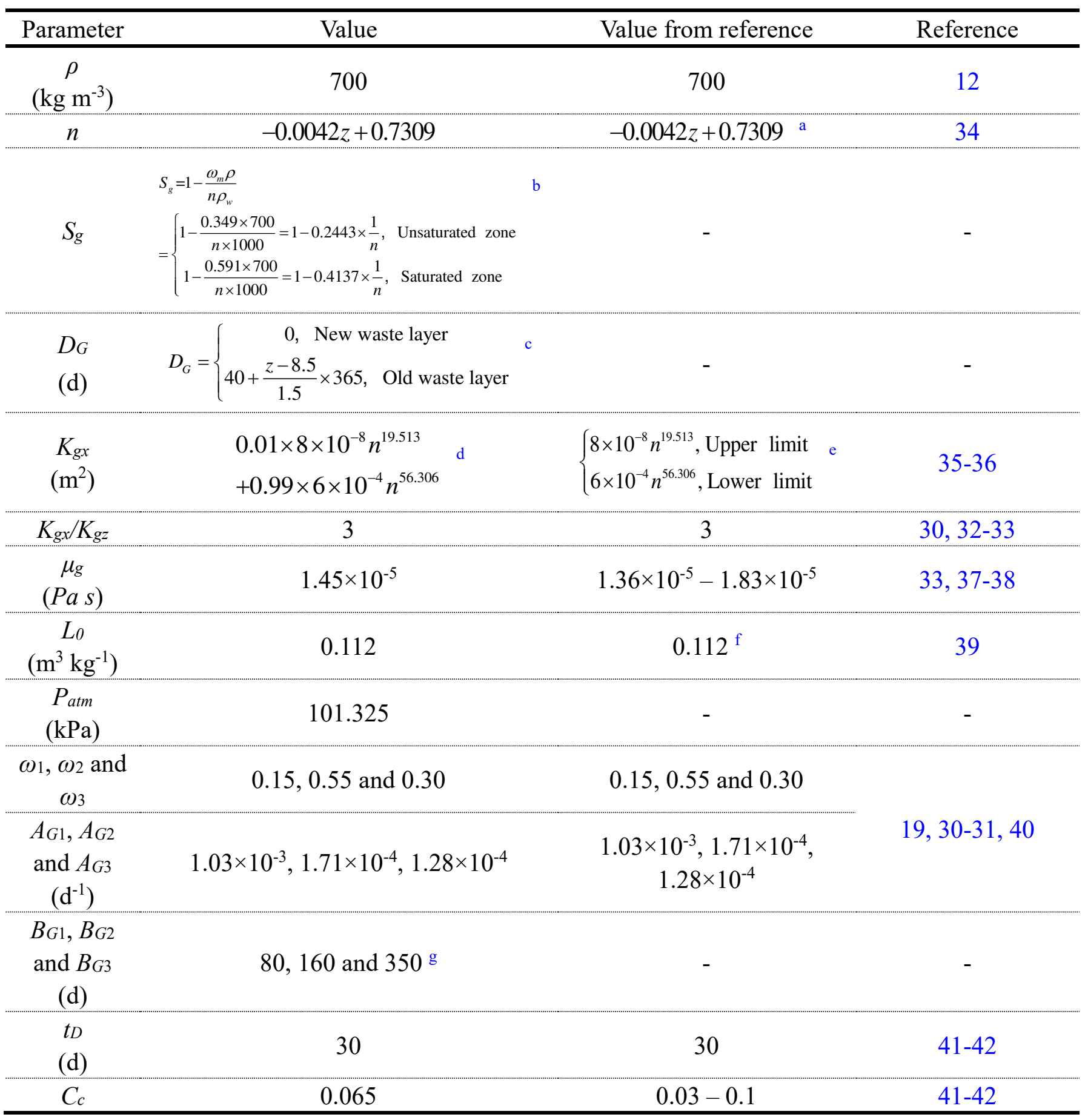

217 Note: a: $n$ is obtained by fitting the porosity in the Suzhou landfill (about $30 \mathrm{~km}$ from the Wuxi

218 landfill), where $z$ is depth;

219 b: Where $\omega_{m}$ is the mass moisture content of waste (the average mass moisture content in saturated 220 and unsaturated areas are $59.1 \%$ and $34.9 \%{ }^{43}$, respectively); $\rho_{w}$ is the water density;

221 c: In order to simulate the gas pressure in the monitoring well, which is placed after the waste body 
222 is excavated, the length of time that waste in the new waste layer has been degraded to produce

223 gas is $0 ; 40$ is the average length of time for the existence of new waste layer (d); 8.5 is the 224 thickness of the new waste layer $(\mathrm{m}) ; 1.5$ is the average height for placing the waste in the old 225 waste layer each year $(\mathrm{m})$;

$226 \mathrm{~d}$ : The fitting curve through the gas permeability in the Suzhou landfill ${ }^{35}$ is selected as the curve 227 of gas permeability in the Wuxi landfill;

228 e: Stoltz et al. ${ }^{36}$ proposed the use the of power function to fit gas permeability, so a power function 229 was used to fit the relationship between gas permeability and porosity measured by Stoltz et al. ${ }^{36}$ 230 to obtain the upper and lower limits of gas permeability in landfills;

$231 \mathrm{f}$ : According to the statistic on the gas production potential of waste in different landfills ${ }^{39}$, the gas 232 production potential of waste in the Hangzhou landfill (about $140 \mathrm{~km}$ from the Wuxi landfill) is 233 found;

$234 \mathrm{~g}$ : The settlement strain obtained from Eq. (6) is multiplied by the thickness of the new waste layer $235(8.59 \mathrm{~m})$ to fit the settlement of the new waste layer in the test area, as is shown in Fig. 4.

236

237

238

239

240

241

242

243

244 direction of the length of the perforated pipe. Then the result obtained by integration is divided by

Fig. 4 Settlement of newly filled MSW layer varies with time

The variation of gas pressure with time in the newly filled MSW layer of the Wuxi landfill was obtained by numerical calculation, as is shown in Fig. 5. Both the theoretical calculation value and the monitoring value of gas pressure show the single peak trend, which is similar to the trend of waste biodegradation rate ${ }^{27}$. It is worth noting that the gas pressure in $\# 0$ well (extraction well) is the mixed gas pressure within the entire perforated pipe (length: $7.7 \mathrm{~m}$ ). In order to calculate the gas pressure in the gas collection well, the gas pressure in the waste body is integrated into the

Time (d)

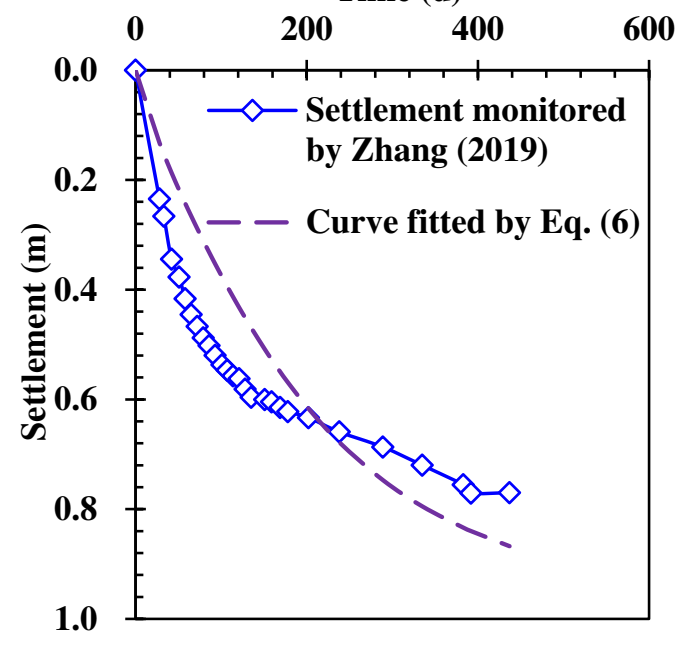


245 the length of the perforated pipe, and the average gas pressure in the gas collection well is obtained,

246 as is shown in Fig. 5(a). When the leachate level is always higher than the bottom of the monitoring

247 well (e.g. \#6 well), or when the bottom of the monitoring well (e.g. \#3well and \#5 well) is

248 submerged due to the increase of leachate level in the later period, the gas pressure below the

249 leachate level is not monitored in the field test of Zhang et al. ${ }^{12}$. However, the gas pressure below

250 the leachate level in the landfill can be theoretically calculated, as is shown in Fig. 5(b) - (d). The

251 calculation value is compared with the field test value in Fig. 5, it can be also found that the

252 variation of gas pressure in the newly filled MSW layer with time is better simulated by the

253 calculation method and numerical model presented in this study.
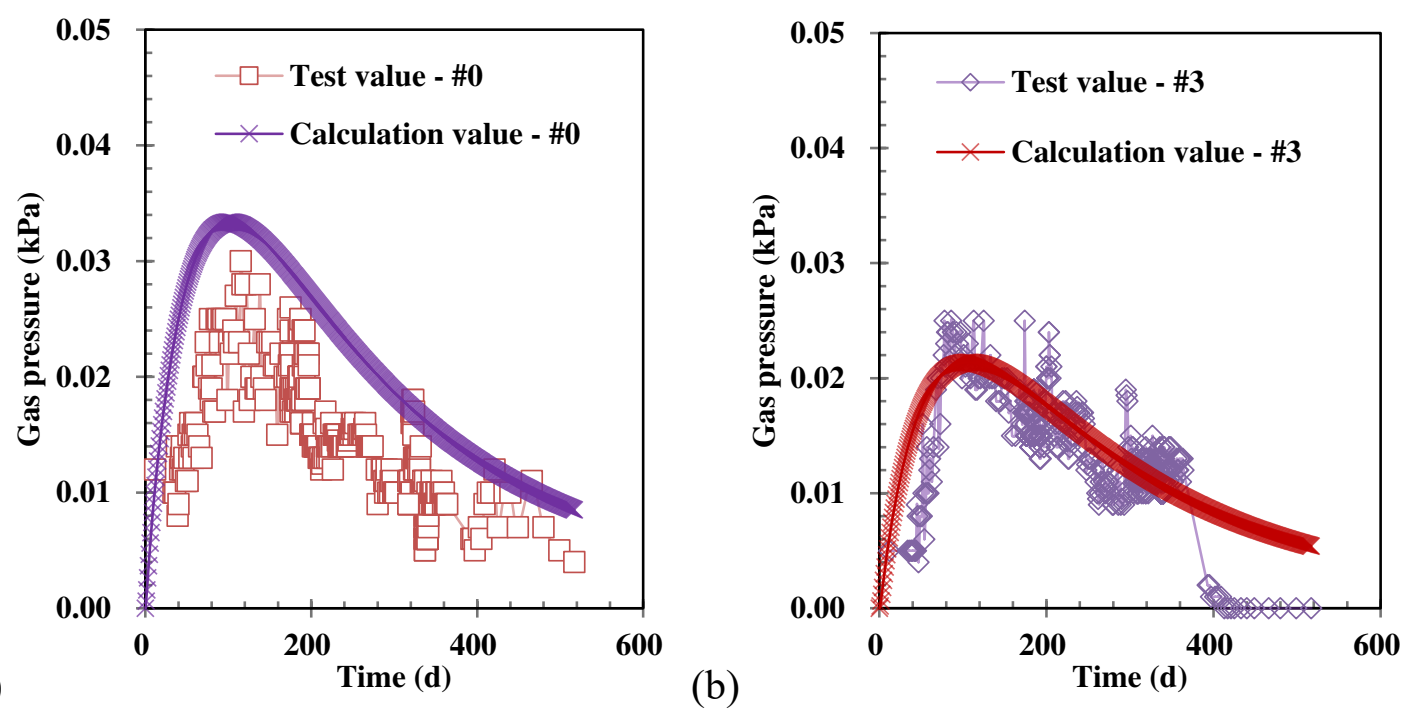


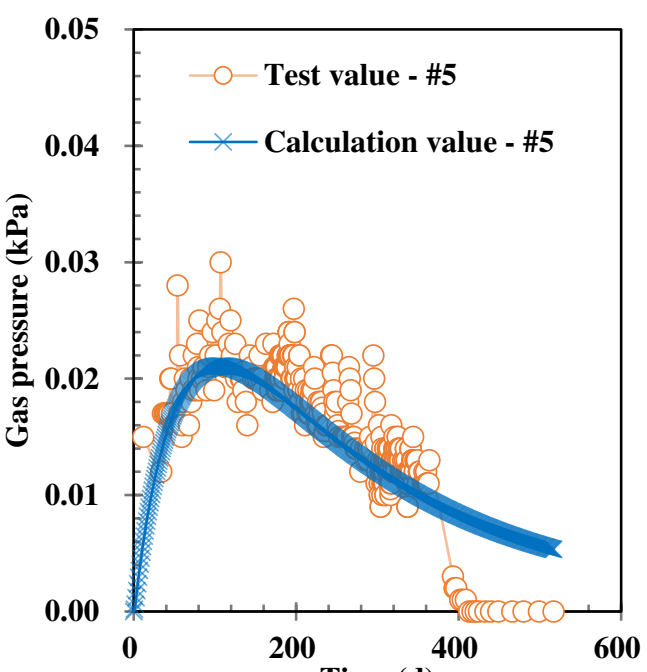

(c)

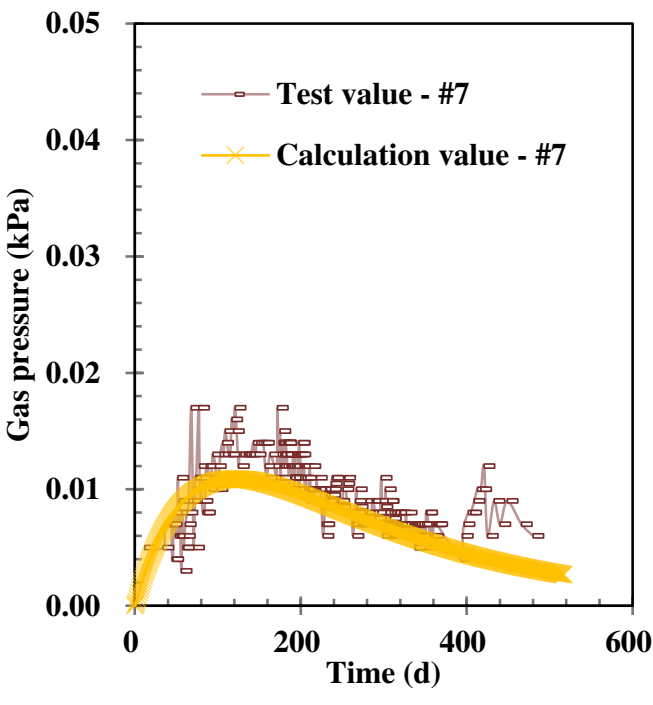

(d)
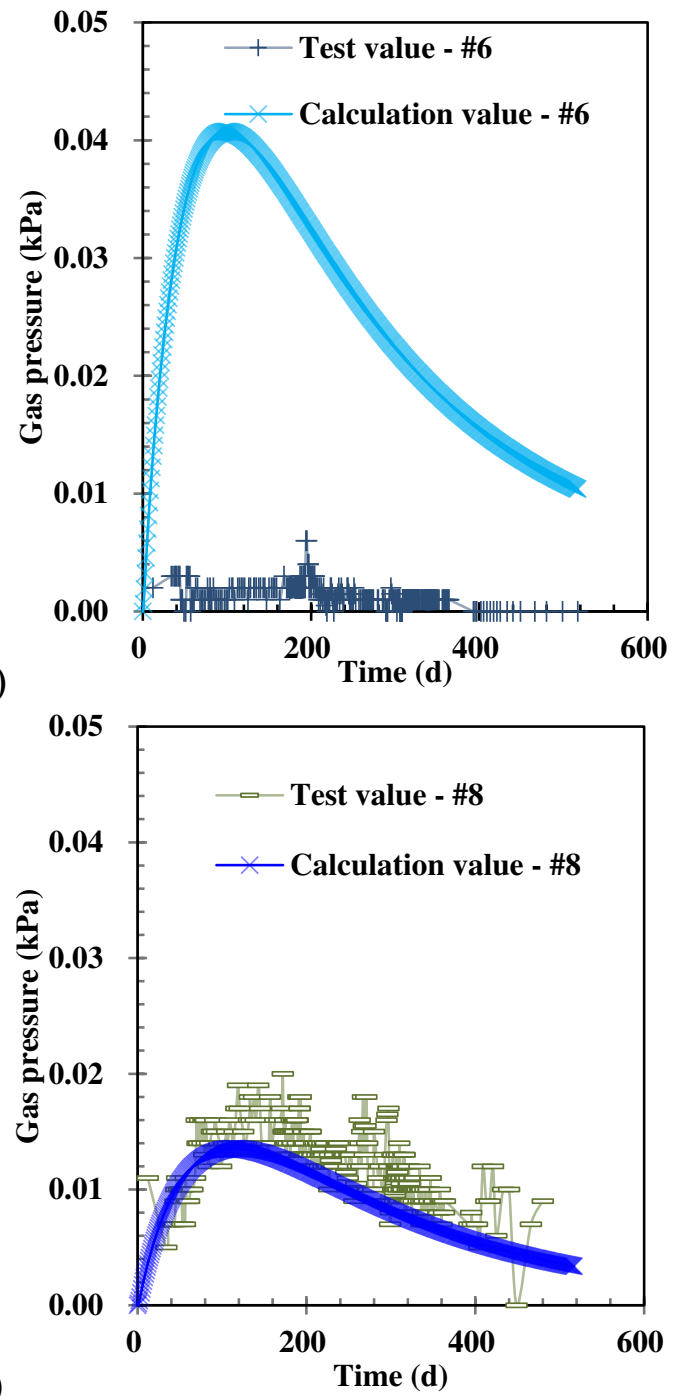

(e)

Fig. 5 Comparison of calculation and test values of gas pressure with time at the bottom of different wells: (a) \#0 well (Depth: 8.74 m); (b) \#3 well (Depth: 3.64 m); (c) \#5 well (Depth: 3.58 m); (d) \#6 well (Depth: 6.56 m); (e) \#7 well (Depth: 1.34 m); (f) \#8 well (Depth: $2.05 \mathrm{~m}$ )

The variation of gas pressure with height in the Wuxi landfill is shown in Fig. 6. The rate of gas production is faster in areas with new waste biodegradation, which leads to an increase in gas pressure within the newly filled MSW layer that increases with depth. As porosity ${ }^{34,44}$ and gas permeability ${ }^{35}$ decrease with depth in landfills, the pore volume and migratory ability of the gas, respectively, also decrease with depth, which ultimately increases gas pressure with depth. According to the ideal gas law, the gas pressure increases with depth under the assumption that the 
gas production yield of new waste is constant.

The waste in the old MSW layer has been buried for a longer period time, and the gas

268 production rate decreases with depth. The gas pressure in the old MSW layer decreases with depth

269 in the earlier period. Therefore, it can be inferred that the maximum gas pressure at this stage

270 occurs where the waste biodegradation rate is not high. According to the result of calculation, this

271 position is in the old MSW layer close to the boundary of the new and old waste layers. At the

272 same time, as the landfill gas in the newly filled MSW layer migrates to the old MSW layer, the

273 gas pressure in the old waste layer begins to increase.

274 As the waste biodegradation rate in the newly filled waste later begins to decrease, the rate of

275 gas pressure increase begins to slow until it ultimately reaches its peak. Due to the migration of

276 landfill gas from the position of high gas pressure to the old MSW layer with low gas pressure, the

277 gas pressure in this layer begins to increase with depth. Therefore, the maximum gas pressure in

278 the later period appears at the bottom of landfill. However, the maximum gas pressure in this period

279 is less than that in the earlier period. Because the landfill gas slowly migrates from the position of

280 higher pressure to the position of lower pressure in the later period, resulting in the gas pressure in

281 the landfill to slowly decrease. The gas pressure gradient in the old waste layer is less than that in

282 the new waste layer, because the waste biodegradation rate in the old waste layer is lower than that

283 in the new waste layer. The gas pressure below the leachate level was not monitored in the field

284 test conducted by Zhang et al. ${ }^{12}$. However, the gas pressure below the leachate level can be

285 obtained by theoretical calculation. It can be also found from Fig. 6 that the calculation method

286 and the numerical model used in this study better reflect the gas pressure distribution in the new 
287 and old waste layers by comparing the calculation value with the test value.
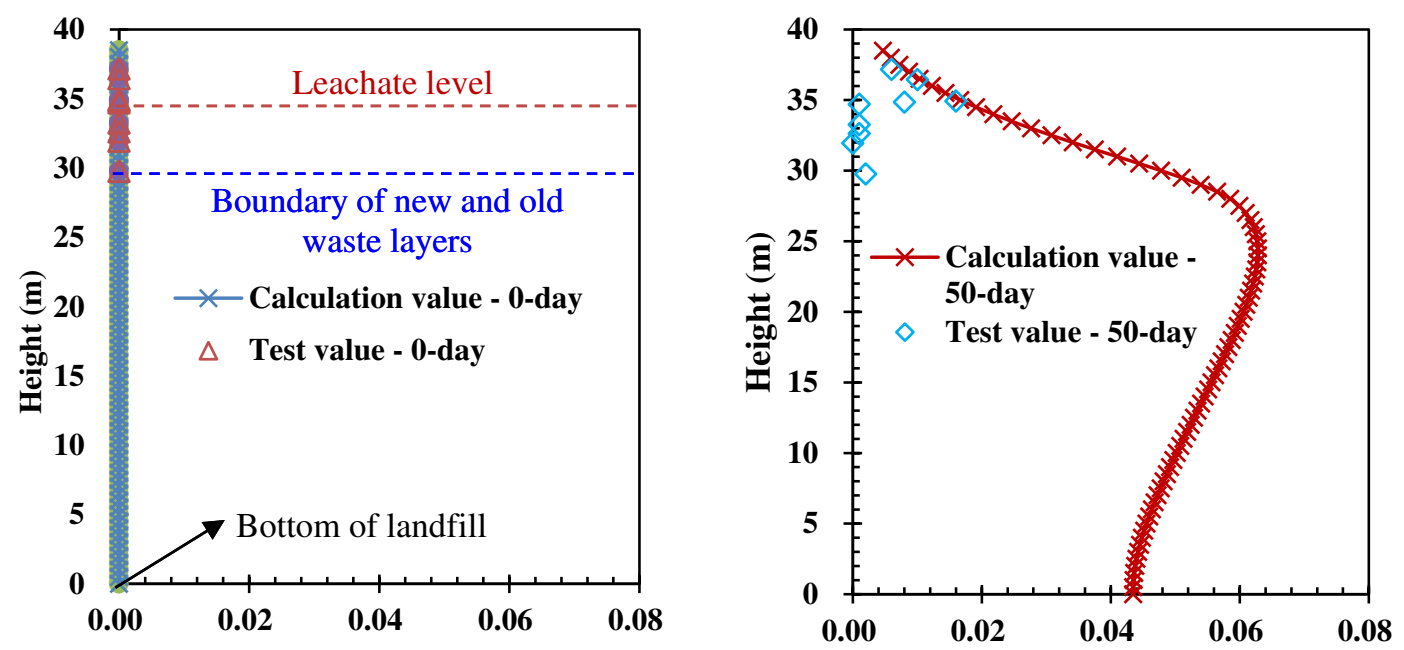

288

(a)

Gas Pressure (kPa)

(b)

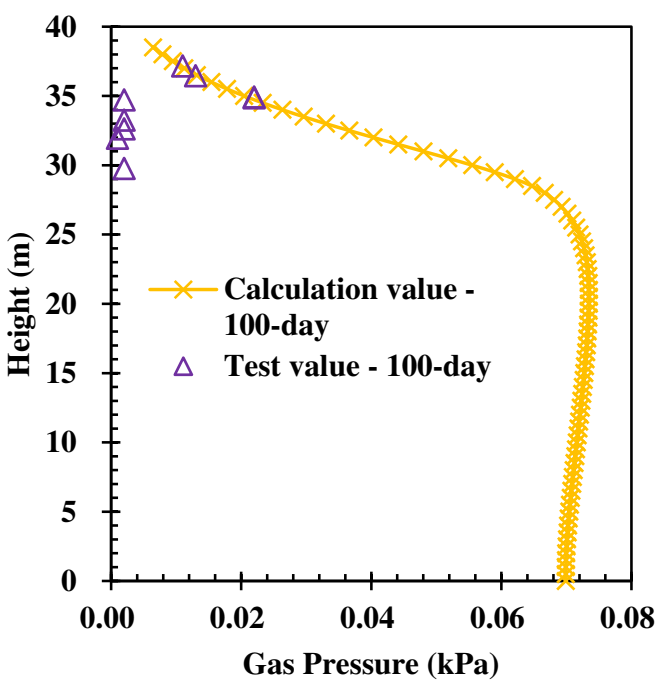

(c)

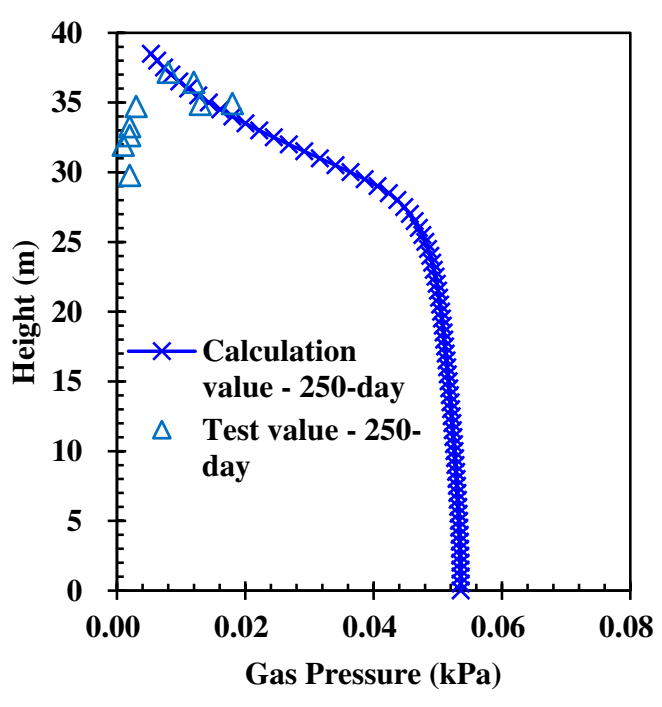

(d)
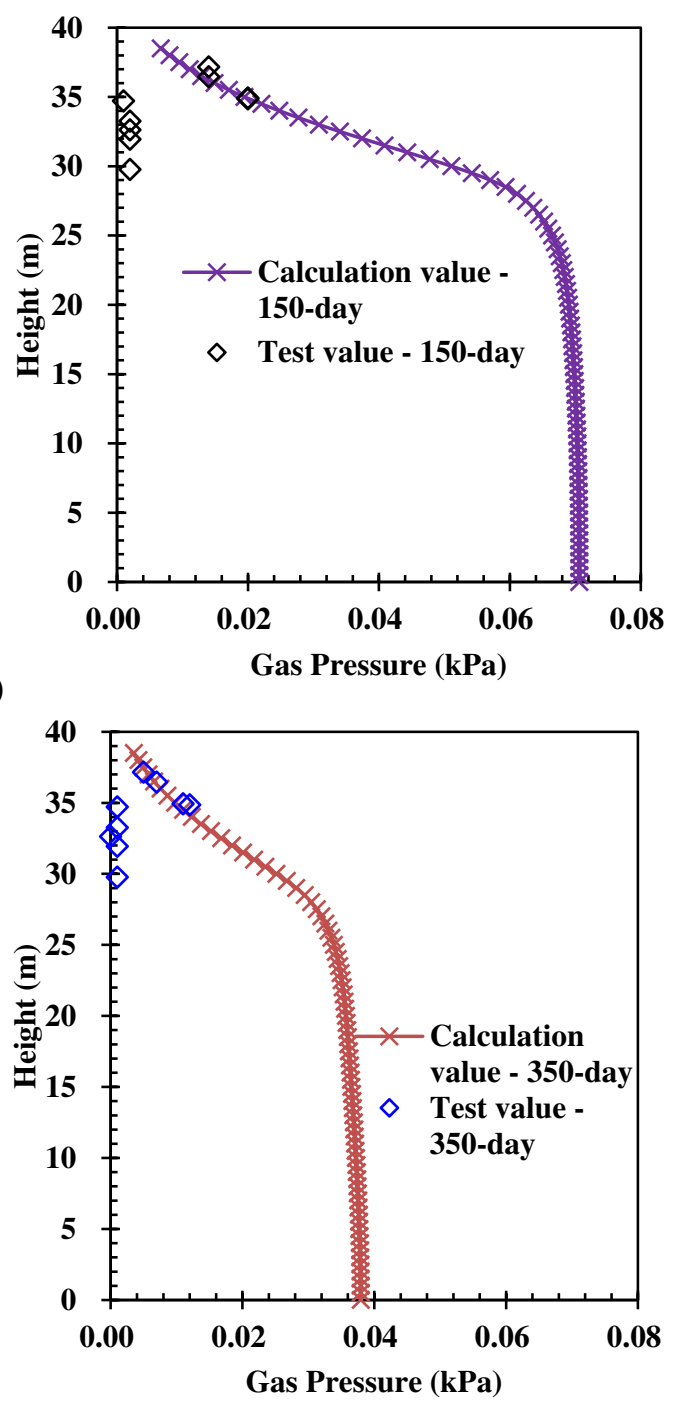
291 Fig. 6 Comparison of calculation and test values of gas pressure with height on the different time:

292 (a) day 0; (b) day 50; (c) day 100; (d) day 150; (e) day 250; (f) day 350

\section{Sensitivity analysis}

296 depth can be obtained, as is shown in Eq. (13):

$$
K_{g x}=\left\{\begin{array}{l}
8 \times 10^{-8} \times(-0.0042 z+0.7309)^{19.513}\left(\mathrm{~m}^{2}\right), \text { Upper limit } \\
6 \times 10^{-4} \times(-0.0042 z+0.7309)^{56.306}\left(\mathrm{~m}^{2}\right), \text { Lower limit }
\end{array} .\right.
$$

298 The comparison of gas pressure distribution under the conditions of different gas permeabilities is

299 shown in Fig. 7(a). It can be found that the smaller the gas permeability, the greater the gas pressure.

300 Because if the gas permeability is smaller, the velocities of gas transport in the horizontal and

301 vertical directions are also smaller. Thus, it becomes difficult for landfill gas to migrate, resulting

302 in larger gas pressure at each subsequent depth. When the gas pressure distribution in a landfill is

303 calculated, the gas permeability that is suitable for the estimated landfill should be selected, and

304 the variation of gas permeability with depth should be considered. If the selected gas permeability

305 is lower than the actual one, it will cause the estimated gas pressure to be larger.

306 The gas production potential of waste is closely related to gas production, Gao et al. ${ }^{39}$ and

307 Zhan et al. ${ }^{45}$ summarized the range of gas production potential, and found this to range from 43.3

308 to $469 \mathrm{~L} \mathrm{~kg}^{-1}$. The comparison of the gas pressure distribution under the conditions of different gas

309 production potentials is shown in Fig. 7(b). It can be found that the greater the gas production

310 potential, the greater the gas pressure in the landfill. Because if the gas production potential is 
311 larger, the concentration of landfill gas produced by waste biodegradation per unit mass is also

312 larger, thus, the gas pressure of landfill gas increases. In the control equation of gas transport (Eq.

313 (7)), larger gas production potential makes the source term of gas production greater, which causes

314 a larger value of gas pressure to be quantified. When the gas pressure distribution in a landfill is

315 calculated, it is necessary to select a gas production potential that relates to actual landfill being

316 studied. If the selected gas production potential is greater than the actual one, it will cause the

317 estimated gas pressure to be overestimated.

(a)

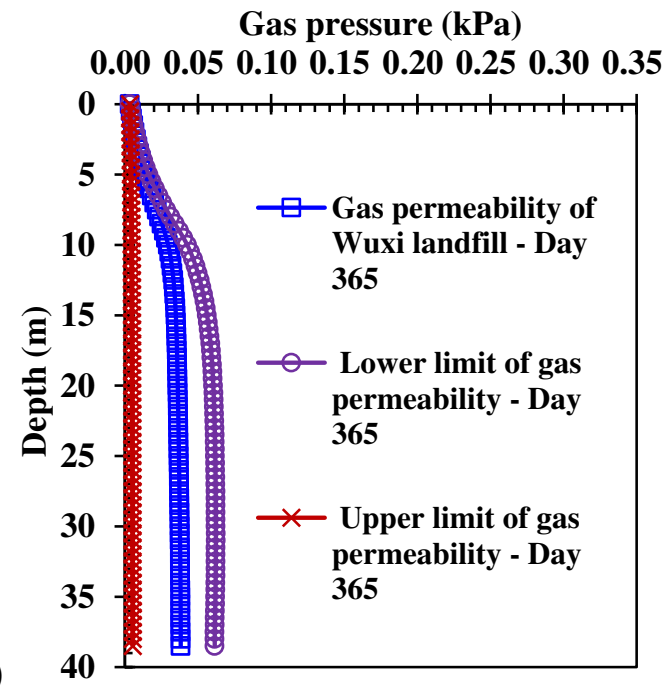

(b)

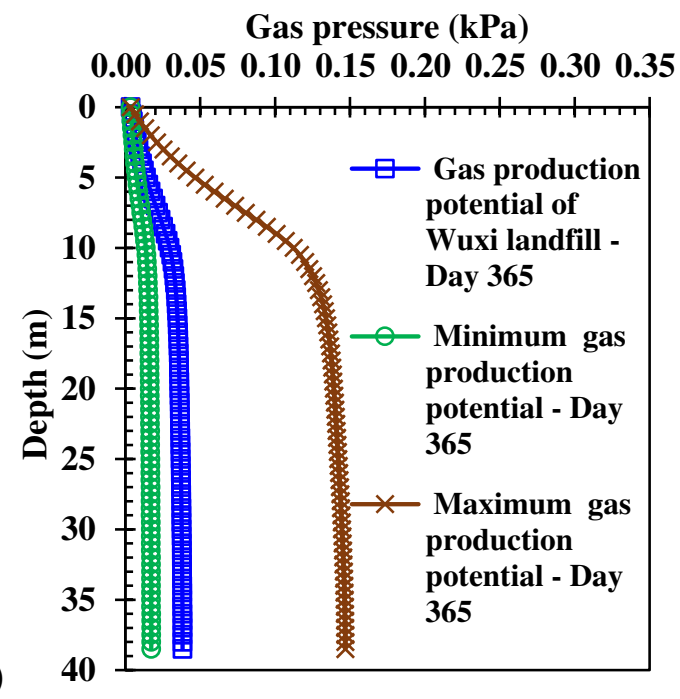

Gas pressure (kPa)

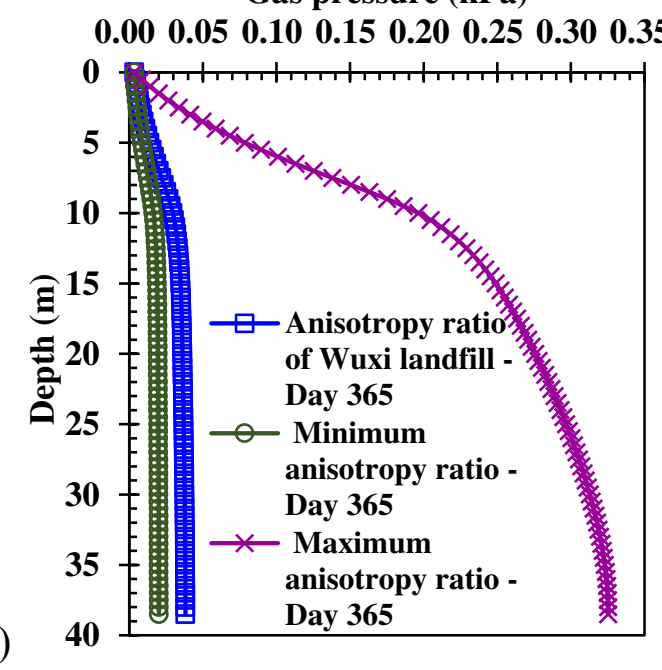

(c)

320 Fig. 7 Comparison of gas pressure distribution under the conditions of different sensitive 
321 parameters: (a) gas permeability; (b) gas production potential; (c) anisotropy ratio

322 The anisotropy ratio of gas permeability (gas permeability in the horizontal direction to gas

323 permeability in the vertical direction) has a great influence on gas pressure ${ }^{32}$. The range of the

324 reported anisotropy ratio of gas permeability is between 1.5 and $20^{32,37,46-47}$. The comparison of

325 the gas pressure distribution under the conditions of different anisotropy ratios is shown in Fig.

$3267(\mathrm{c})$. It can be found that the greater the anisotropy ratio, the greater the gas pressure in the landfill.

327 Because if the anisotropy ratio is larger, the vertical gas permeability is relatively small, making

328 the vertical velocity of gas transport is small as well. This, in turn, makes the resultant velocity of

329 gas transport relatively small, and the landfill gas is more difficult to migrate, ultimately resulting

330 in greater gas pressure with depth. When the gas pressure distribution in a landfill is calculated, it

331 is necessary to select the anisotropy ratio of gas permeability that is suitable for the estimated

332 landfill. If the selected anisotropy ratio is greater than the actual one, it will cause the estimated

333 gas pressure to be overestimated.

334 Using the mathematical model of gas transport developed in this study, the main sensitive

335 parameters to the quantification of gas pressure were analyzed. A larger gas production potential,

336 larger anisotropy ratio, and smaller gas permeability make the gas pressure in a landfill larger,

337 which is beneficial for the collection of landfill gas. However, greater gas pressures adversely

338 affect the stability of landfills and increase the possibility of landfill gas emissions. When gas

339 permeability, gas production potential, and anisotropy ratio increase by $1 \%$, the maximum gas

340 pressures increase by $-0.02 \%, 0.76 \%$, and $1.22 \%$, respectively. Therefore, the gas pressure is most

341 sensitive to the anisotropy ratio of gas permeability. It is very important to select the parameters 
342 that are suitable for the specific landfill when the gas pressure distribution is estimated. In

343 particular, the irrationality of the anisotropy ratio will cause a large error in the estimation of gas

344 pressure.

\section{Conclusions}

346 A one-dimensional gas transport model was established for gas response in a landfill with

347 layered new and old waste. The model takes into account the variation of gas permeability with

348 depth, the anisotropy ratio of gas permeability, and the settlement caused by waste biodegradation.

349 Besides, a single peak model for gas generation is used as the source term of gas production in this

350 model. The stratification of the unsaturated and saturated zones is taken into account by

351 distinguishing the difference in gas saturation. The layering of the new and old waste layers is

352 considered by distinguishing the different length of time that waste has been degraded to produce

353 gas. The time of peak gas production rate is obtained by fitting the settlement of the newly filled

354 MSW layer with the biodegradation settlement equation presented in this study.

355 Based on the numerical calculation method, the gas pressure distribution in the new and old

356 waste layers is obtained. After the results of calculation are compared with the test result, the

357 following conclusions are found: (1) the gas pressure distribution in the landfill with layered new

358 and old waste is better simulated using the gas transport model and the calculation method

359 developed in this study; (2) the time of peak gas production rate fitted by biodegradation settlement

360 is relatively reliable; (3) the maximum gas pressure occurs in the old waste layer near the boundary

361 between new and old waste layers in the earlier period, but moves to the bottom of landfill in the 
362 later period. (4) The anisotropy ratio is a more sensitive parameter influencing the gas pressure

363 distribution. In this study, the gas transport model, the calculation method, and the selection

364 method of parameters provide a theoretical basis for evaluating the variation of gas pressure in a

365 landfill with layered new and old waste.

\section{References}

367 1. El-Fadel, M., Findikakis, A. N. \& Leckie, J. O. Migration and atmospheric emission of landfill

368 gas. Hazard. Waste \& Hazard. Mater. 12(4), 309-327 (1995).

369 2. Powell, J. T., Townsend, T. G. \& Zimmerman, J. B. Estimates of solid waste disposal rates and

370 reduction targets for landfill gas emissions. Nat. Clim. Change. 6(2), 162-165 (2016).

371 3. Mønster, J., Kjeldsen, P. \& Scheutz, C. Methodologies for measuring fugitive methane 372 emissions from landfills - A review. Waste Manage. 87(2019), 835-859 (2019).

373 4. Zhan, L. T., Wu, T., Feng, S., Lan, J. W. \& Chen, Y. M. A simple and rapid in situ method for 374 measuring landfill gas emissions and methane oxidation rates in landfill covers. Waste Manage.

$375 \quad \&$ Res. 38(5), 588-593 (2020).

376 5. Thiel, R. S. Design methodology for a gas pressure relief layer below a geomembrane landfill 377 cover to improve slope stability. Geosynth. Int. 5(6), 589-617 (1998).

378 6. Blight, G. Slope failures in municipal solid waste dumps and landfills: A review. Waste $379 \quad$ Manage. \& Res. 26(5), 448-463 (2008).

3807 7. Ma, P. C., Ke, H., Lan, J. W., Chen, Y. M. \& He, H. J. Field measurement of pore pressures 381 and liquid-gas distribution using drilling and ERT in a high food waste content MSW landfill 
in Guangzhou, China. Eng. Geol. 250(2019), 21-33 (2019).

383 8. Kjeldsen, P. \& Fischer, E. V. Landfill gas migration - Field investigations at Skellingsted 384 landfill, Denmark. Waste Manage. \& Res. 13(5), 467-484 (1995).

385 9. Spokas, K. A. \& Bogner, J. E. Field system for continuous measurement of landfill gas 386 pressures and temperatures. Waste Manage. \& Res. 14(3), 233-242 (1996).

387 10. Bentley, H. W., Smith, S. J., Tang, J. \& Walter, G. R. A method for estimating the rate of 388 landfill gas generation by measurement and analysis of barometric pressure waves. In: 389 Proceedings of the 18th International Conference on Solid Waste Technology and $390 \quad$ Management, Philadelphia, USA (2003).

391 11. Gebert, J. \& Groengroeft, A. Passive landfill gas emission - Influence of atmospheric pressure 392 and implications for the operation of methane-oxidising biofilters. Waste Manage. 26(3), 245$251(2006)$.

394 12. Zhang, T., Shi, J. Y., Qian, X. D. \& Ai, Y. B. Temperature and gas pressure monitoring and 395 leachate pumping tests in a newly filled MSW layer of a landfill. Int. J. Environ. Res. 13(1), $396 \quad 1-19(2019)$.

397 13. Lefebvre, X., Lanini, S. \& Houi, D. The role of aerobic activity on refuse temperature rise, I. 398 Landfill experimental study. Waste Manage. \& Res. 18(5), 444-452 (2000).

399 14. Jang, Y. S. \& Kim, Y. I. Behavior of a municipal landfill from field measurement data during 400 a waste-disposal period. Environ. Earth Sci. 44(5), 592-598 (2003).

401 15. Findikakis, A. N. \& Leckie, J. O. Numerical simulation of gas flow in sanitary landfills. J. 402 Environ. Eng. Div. 105(5), 927-945 (1979). 
16. Findikakis, A. N., Papelis, C., Halvadakis, C. P. \& Leckie, J. O. Modelling gas production in managed sanitary landfills. Waste Manage. \& Res. 6(2), 115-123 (1988).

17. Nastev, M., Therrien, R., Lefebvre, R. \& Gélinas, P. Gas production and migration in landfills and geological materials. J. Contam. Hydrol. 52(1), 187-211 (2001).

18. Merry, S. M., Fritz, W. U., Budhu, M. \& Jesionek, K. Effect of gas on pore pressures in wet landfills. J. Geotech. \& Geoenviron. Eng. 132(5), 553-561 (2006).

19. Yu, L., Batlle, F. \& Lloret, A. A coupled model for prediction of settlement and gas flow in MSW landfills. Int. J. Numer. \& Anal. Methods Geomech. 34(11), 1169-1190 (2010).

20. Garg, A. \& Achari, G. A. Comprehensive numerical model simulating gas, heat, and moisture transport in sanitary landfills and methane oxidation in final covers. Environ. Model. \& Assess. 15(5), 397-410 (2010).

21. Feng, S. J. \& Zheng, Q. T. A two-dimensional gas flow model for layered municipal solid waste landfills. Comput. \& Geotech. 63(2015), 135-145 (2015).

22. Kutsyi, D. V. Numerical modeling of landfill gas and heat transport in the deformable MSW landfill body. Part 1. Development of the model. Therm. Eng. 2015, 62(6), 403-407 (2015).

23. Lu, S. F., Xiong, J. H., Feng, S. J., Chen, H. X. \& Bai, Z. B. A numerical model for 419 biodegradable-hydraulic-gaseous-mechanical behaviors in landfills using finite volume 420 method. In: Proceedings of the 2nd Symposium on Coupled Phenomena in Environmental 421 Geotechnics, Leeds, UK (2017).

422 24. Lu, S. F., Xiong, J. H., Feng, S. J., Chen, H. X., Bai, Z. B., Fu, W. D. \& Lü, F. A finite-volume 423 numerical model for bio-hydro-mechanical behaviors of municipal solid waste in landfills. 
Comput. \& Geotech. 109(2019), 204-219 (2019).

425 25. Xue, Q., Feng, X. T. \& Liang, B. Slippage solution of gas pressure distribution in process of 426 landfill gas seepage. Appl. Math. \& Mech. 26(12), 1623-1633 (2005).

427 26. Townsend, T. G., Wise, W. R. \& Jain, P. One-dimensional gas flow model for horizontal gas 428 collection systems at municipal solid waste landfills. J. Environ. Eng. 131(12), 1716-1723 (2005).

430 27. Liu, X. D., Shi, J. Y, Qian, X. D., Hu, Y. D. \& Peng, G. One-dimensional model for municipal 431 solid waste (MSW) settlement considering coupled mechanical-hydraulic-gaseous effect and 432 concise calculation. Waste Manage. 31(12), 2473-2483 (2011).

433 28. Li, Y. C., Cleall, P. J., Ma, X. F., Zhan, T. L. T. \& Chen, Y. M. Gas pressure model for layered 434 municipal solid waste landfills. J. Environ. Eng. 138(7), 752-760 (2012).

435 29. Li, Y. C., Zheng, J., Chen, Y. M. \& Guo, R. Y. One-dimensional transient analytical solution 436 for gas pressure in municipal solid waste landfills. J. Environ. Eng. 139(12), 1441-1445 $437 \quad(2013)$.

438 30. Arigala, S. G., Tsotsis, T. T., Webster, I. A., Yortsos, Y. C. \& Kattapuram, J. J. Gas generation, 439 transport, and extraction in landfills. J. Environ. Eng. 121(1), 33-44 (1995).

440 31. Feng, Q. L., Liu, L., Xue Q. \& Zhao, Y. Landfill gas generation and transport in bioreactor 441 landfill. In: Proceedings of International Symposium on Geoenvironmental Engineering, 442 Hangzhou, China (2010).

443 32. Young, A. Mathematical modeling of landfill gas extraction. J. Environ. Eng. 115(6), 1073$4441087(1989)$. 
445 33. Xi, Y. \& Xiong, H. Numerical simulation of landfill gas pressure distribution in landfills.

$446 \quad$ Waste Manage. \& Res. 31(11),1140-1147 (2013).

447 34. Chen, Y. M., Zhan, T. L. T., Wei, H. Y. \& Ke, H. Aging and compressibility of municipal solid $448 \quad$ wastes. Waste Manage. 29(1), 86-95 (2009).

449 35. Wei, H. Y., Zhan, L. T., Chen, Y. M. \& Ling, D. S. One-dimensional gas migration in multi$450 \quad$ layered landfills of municipal solid wastes. Chin. J. Geotech. Eng. 31(11), 1665-1671 (2009). $451 \quad$ (In Chinese)

452 36. Stoltz, G., Gourc, J. P. \& Oxarango, L. Liquid and gas permeabilities of unsaturated municipal 453 solid waste under compression. J. Contam. Hydrol. 118(1), 27-42 (2010).

454 37. Liu, L., Liang, B., Xue, Q., Zhao, Y. \& Yang, C. The modelling of biochemical-thermal 455 coupling effect on gas generation and transport in MSW landfill. Int. J. Environ. \& Pollut. $456 \quad 46(3-4), 216-233(2011)$.

457 38. Guan, C., Xie, H., Qiu, Z., Chen, Y. \& Chen, P. One-dimensional coupled model for landfill 458 gas and water transport in layered unsaturated soil cover systems. J. Zhejiang Univ. Sci. 17(8), 667-676 (2016).

460 39. Gao, W., Chen, Y. M., Zhan, L. T. \& Bian, X. C. Engineering properties for high kitchen waste 461 content municipal solid waste. J. Rock. Mech. \& Geotech. Eng. 7(6), 646-658 (2015).

462 40. Zeng, G. Study on landfill gas migration in landfilled municipal solid waste based on gas463 solid coupling model. Environ. Prog. 39(2), 1-8 (2020).

464 41. Sowers, G. F. Settlement of waste disposal fills. In: Proceeding of Eighth International 465 Conference on Soil Mechanics and Foundation Engineering, Moscow, Russia (1973). 
42. Qian, X. D., Shi, J. Y. \& Liu, X. D. Design and Construction of Modern Sanitary Landfill (2nd edition), China Architecture and Building Press, Beijing (2011). (In Chinese)

43. Zhang, T. Study on liquid-thermal-gaseous response in a newly filled municipal solid waste layer. PHD Thesis, Hohai University, Nanjing, China (2019). (In Chinese)

470 44. Feng, S. J., Gao, K. W., Chen, Y. X., Li, Y., Zhang, L. M. \& Chen, H. X. Geotechnical 471 properties of municipal solid waste at Laogang Landfill, China. Waste Manage. 63(2017), $472 \quad 354-365$ (2017).

473 45. Zhan, T. L. T., Xu, X. B., Chen, Y. M., Ma, X. F. \& Lan, J. W. Dependence of gas collection 474 efficiency on leachate level at wet municipal solid waste landfills and its improvement 475 methods in China. J. Geotech. \& Geoenviron. Eng. 141(4), 4015002 (2015).

476 46. Peng, X. Y. \& Yu, Y. Experimental study on air permeability of compacted MSW by a landfill 477 lysimeter. Acta. Sci. Circum. 23(4), 530-534 (2003). (In Chinese)

478 47. Liu, H. L., He, H. J. \& Lan, J. W. Influences of leachate level on landfill gas collection. J. 479 Water Resour. \& Archit. Eng. 15(5), 129-133 (2017). (In Chinese)

\section{Acknowledgments}




\section{Author contributions}

485 T. Zhang and J. Y. Shi developed the study and wrote the original manuscript, X. Wu did the

486 numerical analysis, L. Hai \& X. L. Li performed the data collection and analysis, and generated 487 the figures and tables.

\section{Competing interests}

489 The authors declare no competing interests.

\section{$490 \quad$ Additional information}

491 Correspondence and requests for materials should be addressed to T. Zhang. 
Figures

\section{Initial time}

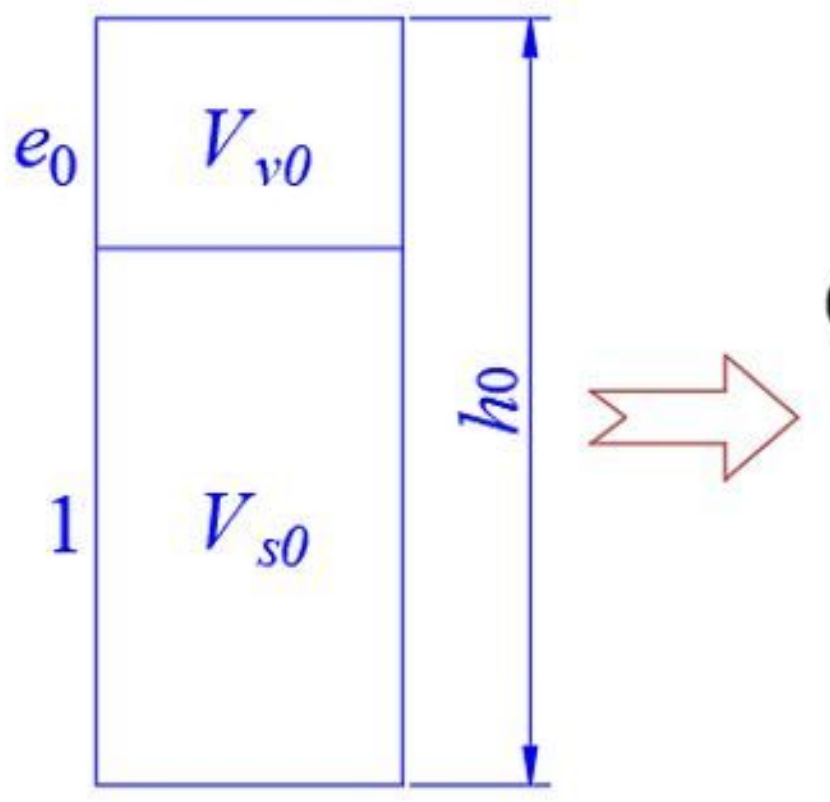

Time $t$

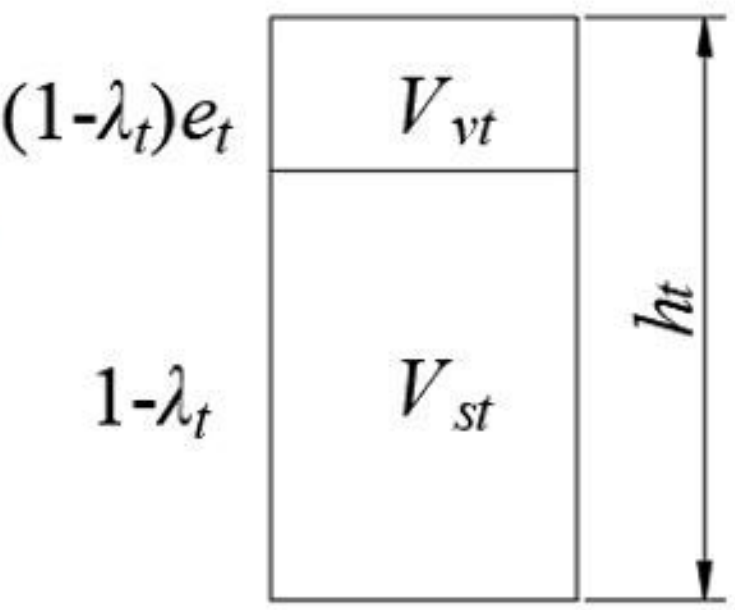

Figure 1

Schematic diagram of simplified landfill

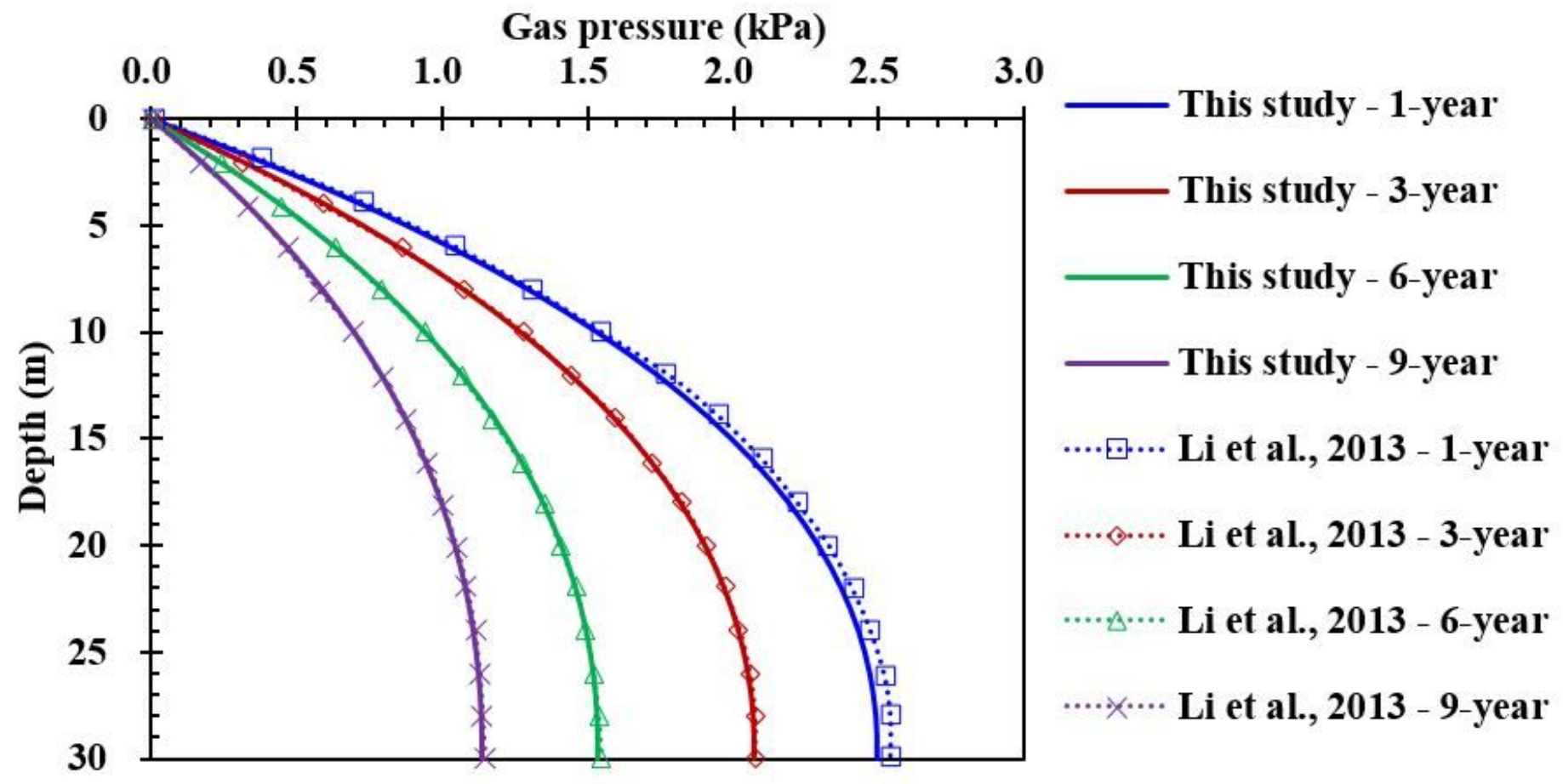


Figure 2

Comparison of the calculation values of gas pressure in this study and the value calculated by Li et al.29

Upper boundary: $P_{g}(z=1.3, t)=0.0002713 t \times e^{-\frac{t}{135}}$

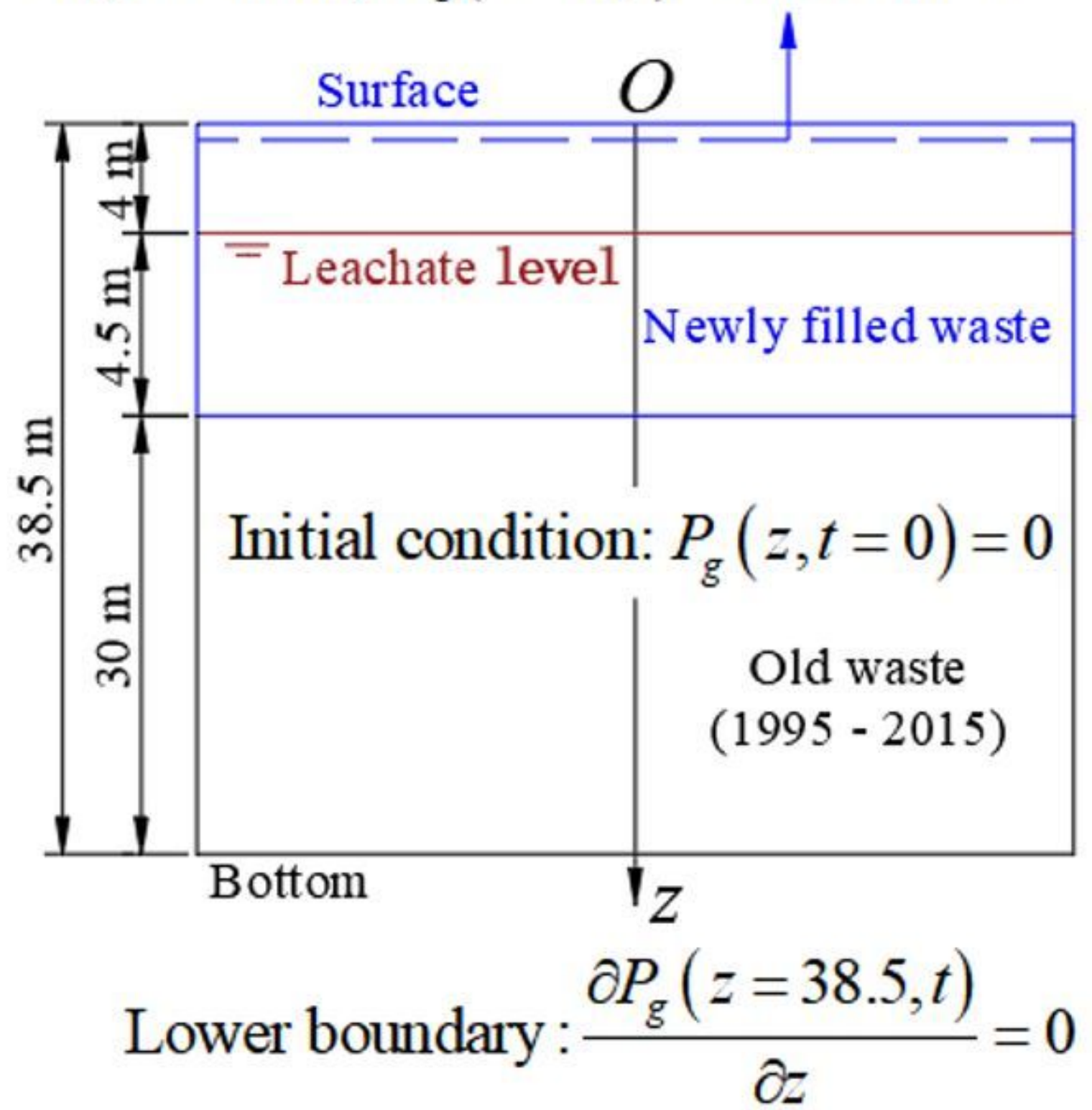

Figure 3

Physical model for gas transport in the Wuxi landfill 


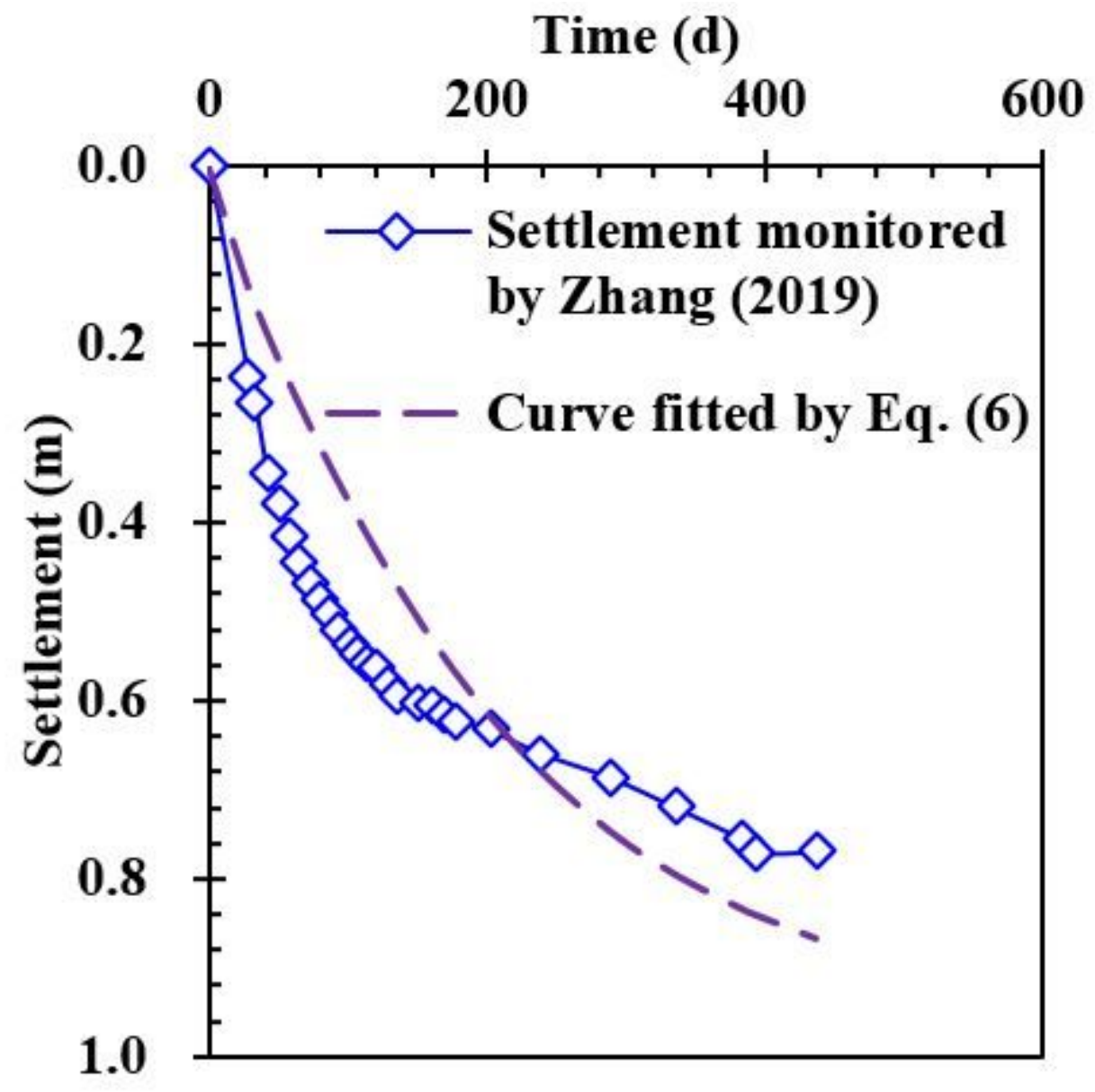

Figure 4

Settlement of newly filled MSW layer varies with time 


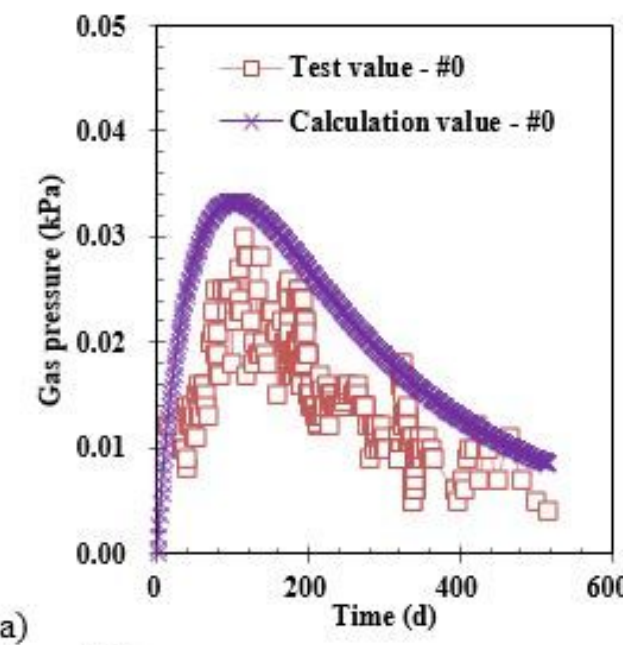

(a)

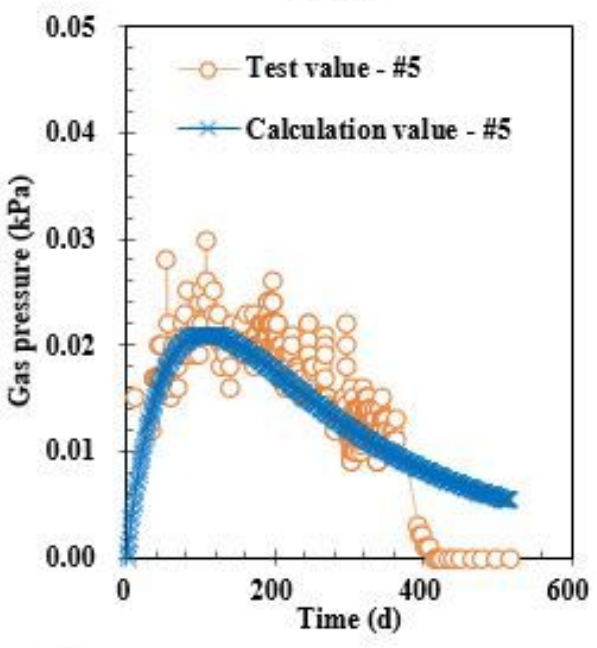

(c)

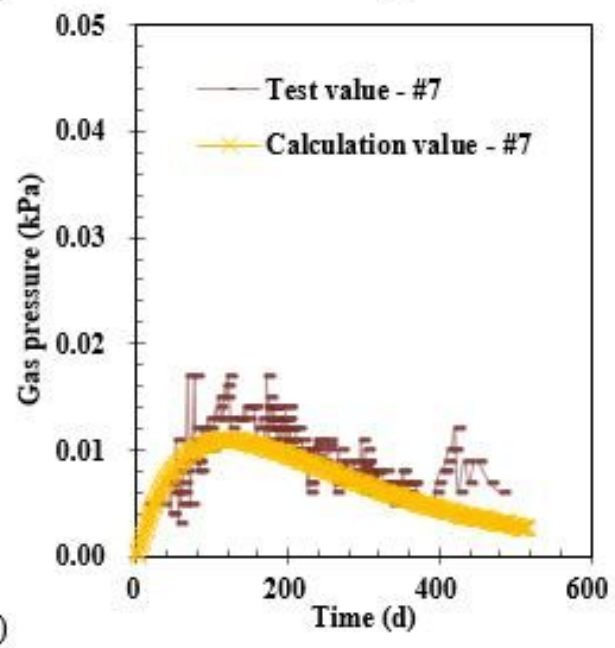

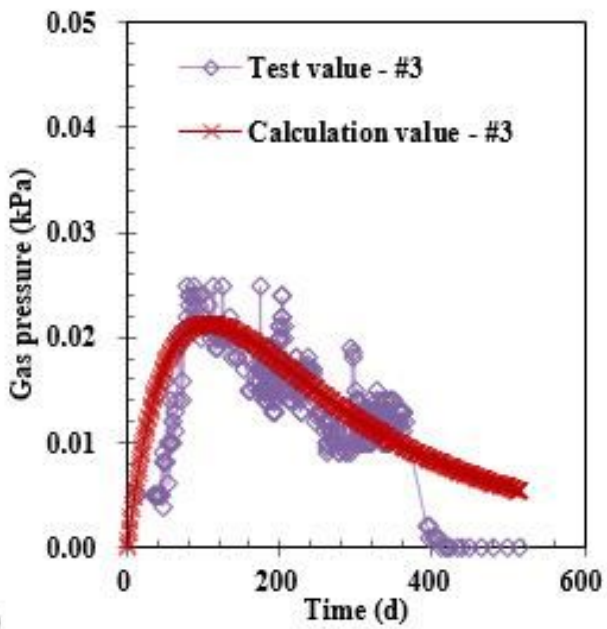

(b)

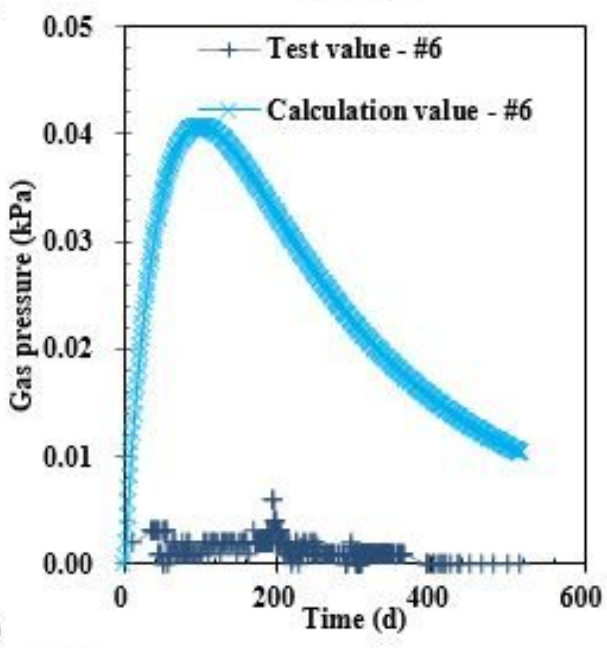

(d)

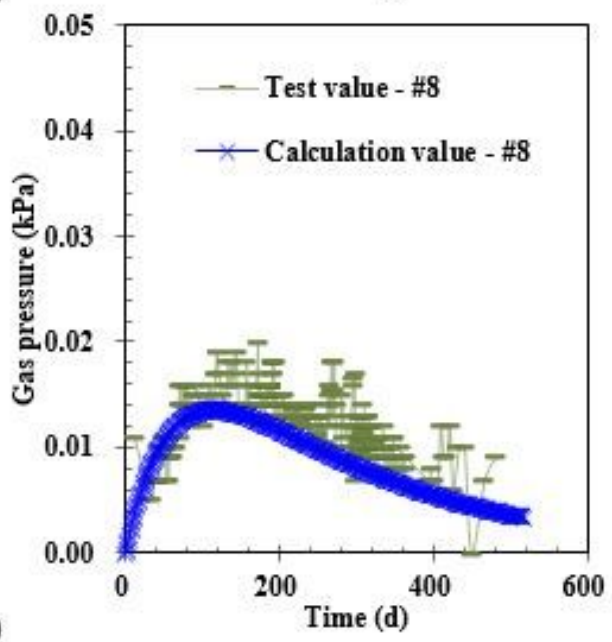

\section{Figure 5}

Comparison of calculation and test values of gas pressure with time at the bottom of different wells: (a) \#0 well (Depth: 8.74 m); (b) \#3 well (Depth: 3.64 m); (c) \#5 well (Depth: 3.58 m); (d) \#6 well (Depth: 6.56 m); (e) \#7 well (Depth: 1.34 m); (f) \#8 well (Depth: 2.05 m) 

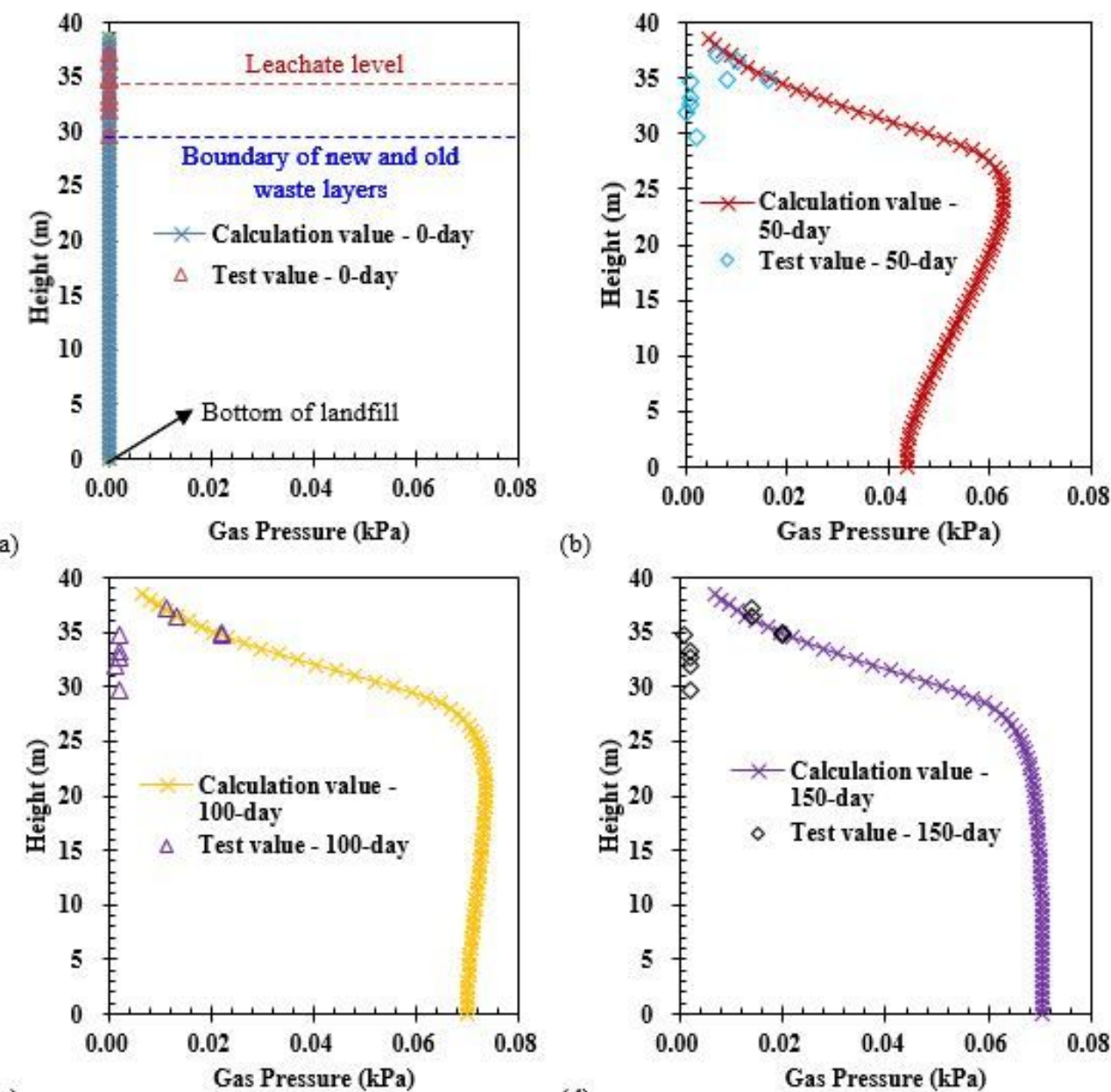

(b)

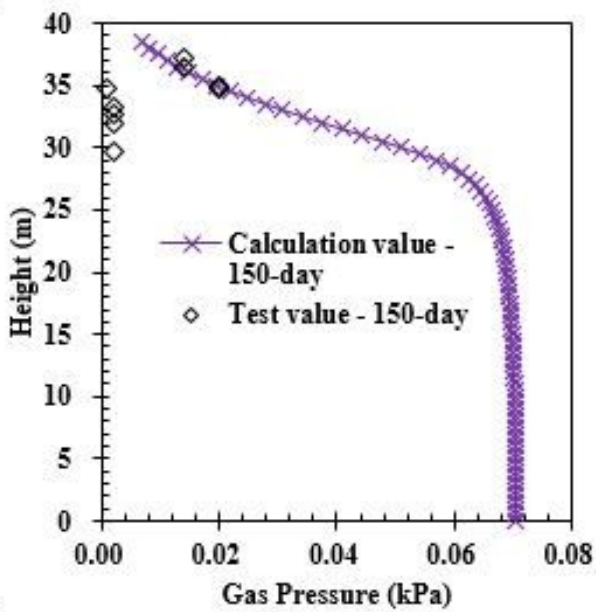

(c)

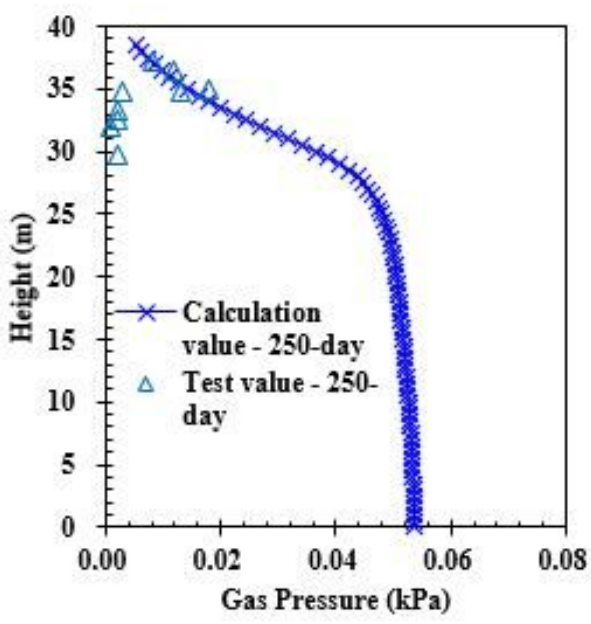

(d)

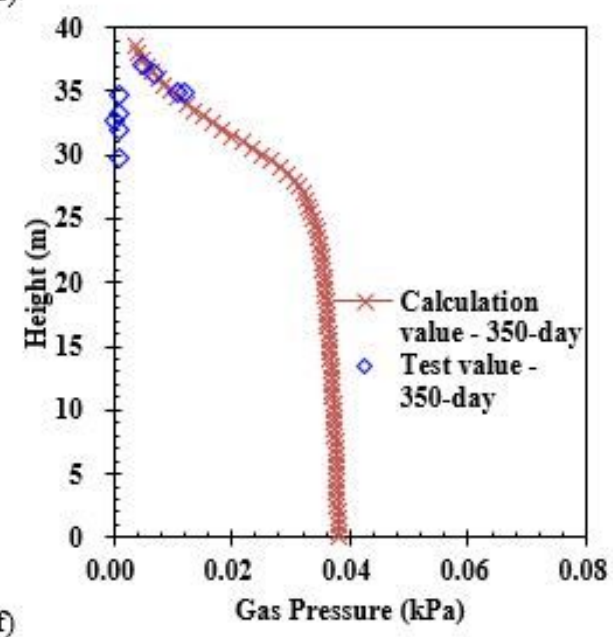

Figure 6

Comparison of calculation and test values of gas pressure with height on the different time: (a) day 0; (b) day 50; (c) day 100; (d) day 150; (e) day 250; (f) day 350 
Gas pressure (kPa)

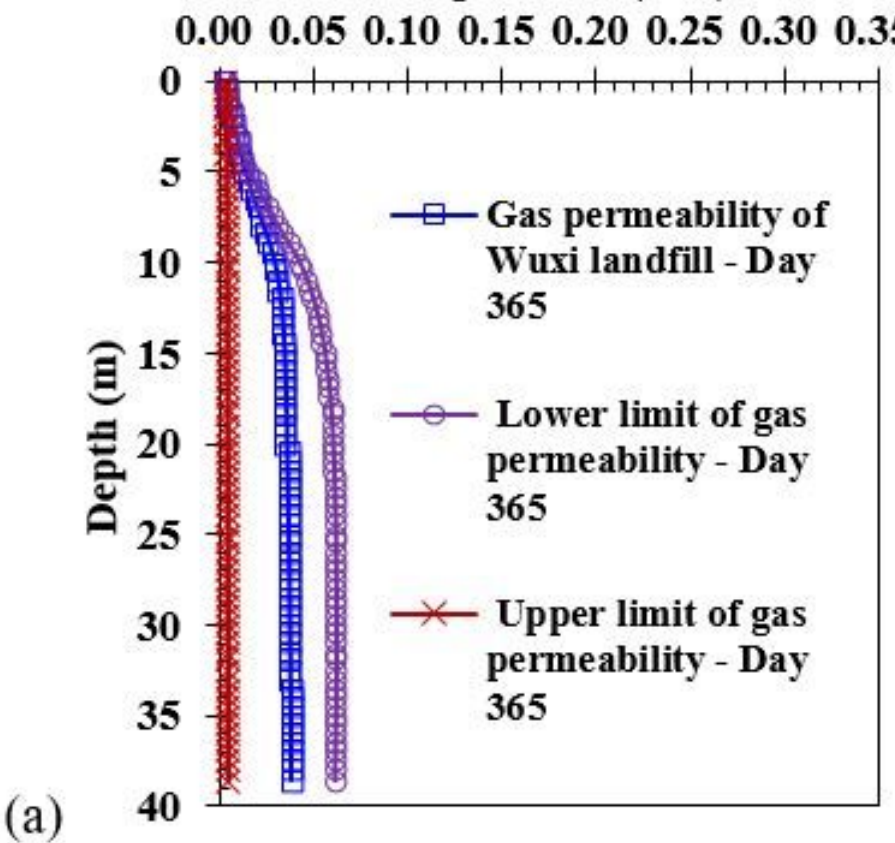

Gas pressure (kPa)

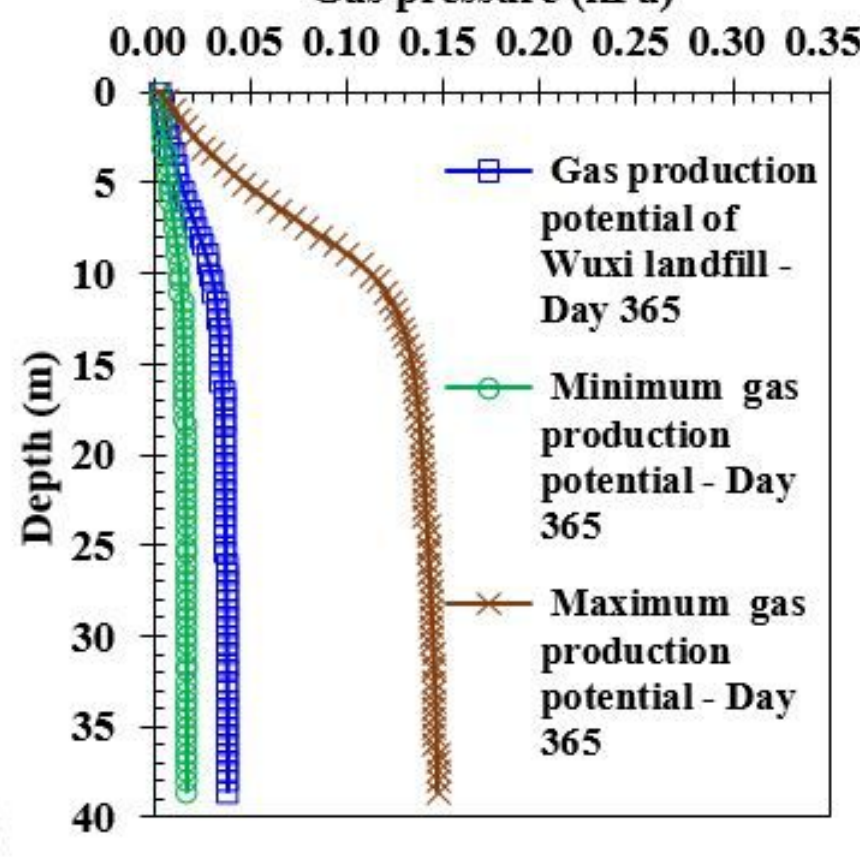

(b)

Gas pressure (kPa)

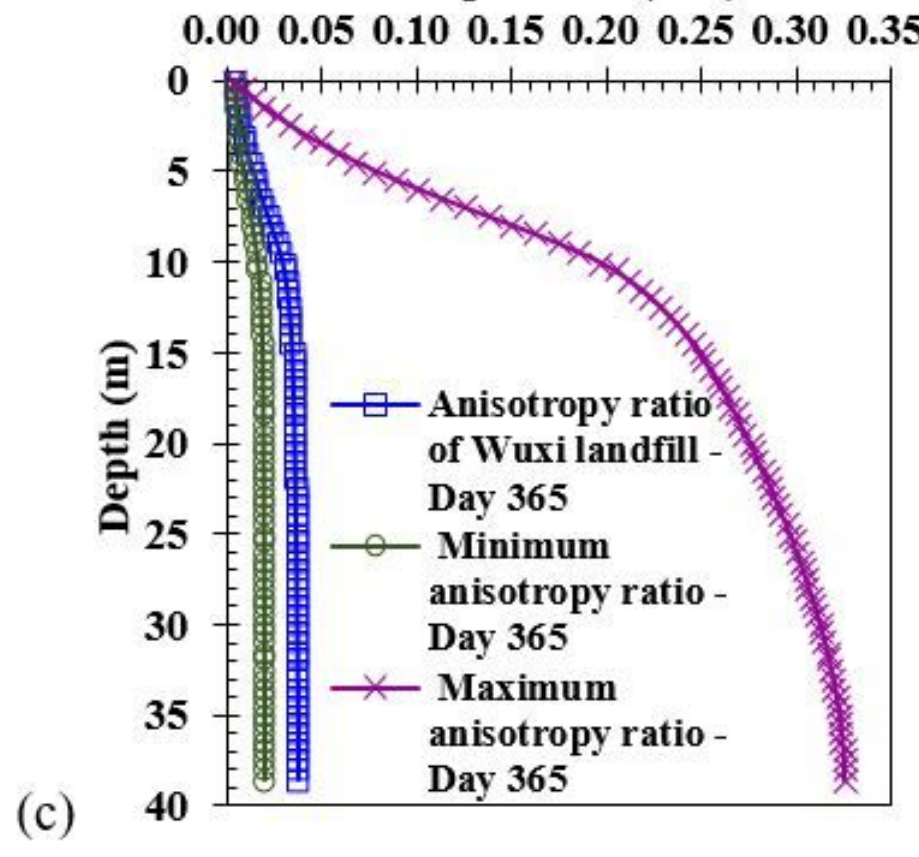

Figure 7

Comparison of gas pressure distribution under the conditions of different sensitive parameters: (a) gas permeability; (b) gas production potential; (c) anisotropy ratio

\section{Supplementary Files}

This is a list of supplementary files associated with this preprint. Click to download. 